\title{
Reflexões sobre 0 aleitamento materno em tempos de pandemia por COVID-19
}

\author{
Reflections on breastfeeding and COVID-19 \\ Reflexiones sobre la lactancia materna y COVID-19 \\ Mauren Teresa Grubisich Mendes Tacla ${ }^{1}$ (D) https://orcid.org/0000-0001-8928-3366 \\ Edilaine Giovanini Rossetto ${ }^{1}$ (D) https://orcid.org/0000-0002-0996-5154 \\ Geisa Marcela Perdigão ${ }^{1}$ (D) https://orcid.org/0000-0002-8220-6023 \\ Edrian Maruyama Zani ${ }^{1}$ (D) https://orcid.org/0000-0002-1759-4744 \\ Isabella Vicente da Silva ${ }^{1}$ (D) htps://orcid.org/0000-0002-0200-5716
}

\section{Resumo}

Objetivo: prover uma reflexão sobre as evidências científicas relacionadas com o aleitamento materno publicadas na literatura em tempos de pandemia por COVID-19.

Métodos: Revisão de escopo nas bases MEDLINE/PubMed, CINAHL, BDENF, Scopus e LILACS, no período de 1 de janeiro a 15 de julho de 2020.

Resultados: Do total de 21.697 artigos, 28 foram incluídos na revisão. Os resultados reuniram a falta de evidências suficientes para elucidar o processo de transmissibilidade perinatal e os métodos de detecção do SARS-CoV2 relacionados ao aleitamento materno e divergências entre os pesquisadores quanto ao estabelecimento da amamentação nos casos de mulheres confirmadas ou suspeitas para infecção por COVID-19.

Conclusão: Balanceando os benefícios comprovados para mãe e filho pela prática do aleitamento materno com os malefícios advindos das manifestações da infecção por COVID-19, essa revisão aponta um pacote de cuidados favorável à manutenção da amamentação a partir do que se tem conhecido até o momento.

\section{Abstract}

Objective: Provide a reflection on the scientific evidence related to breastfeeding published in the literature in times of pandemic by COVID-19.

Methods: Revisions in scope in the MEDLINE/PubMed, CINAHL, BDENF, Scopus and LILACS bases, in the period from $1^{\text {st }}$ January to $15^{\text {th }}$ July 2020.

Results: From a total of 21.697 articles, 28 were included in the review. The results gathered the lack of evidence enough to elucidate the processes of perinatal transmissibility and the methods of SARS-CoV2-detection related to breastfeeding, and the divergences among the researchers in the matters of maintaining breastfeeding in cases of confirmed or suspected women for COVID-19-infection.

Conclusion: Balancing the proven benefits for mother and child through the practice of breastfeeding with the harms arising from the manifestations of COVID-19-infection, this review points out a package of care favorable to the maintenance of the breastfeeding from what has been proven to be scientifically known until now.

\section{Resumen}

Objetivo: Proporcionar una reflexión sobre la evidencia científica relacionada con la lactancia materna publicada en la literatura en tiempos de pandemia por COVID-19.

Métodos: Revisión del alcance ejecutada en las bases MEDLINE / PubMed, CINAHL, BDENF, Scopus y LILACS, del 1 de enero a 15 de julio de 2020.

Resultados: Del total de 21,697 artículos, 28 fueron incluidos en la revisión. Los resultados reunieron la falta de evidencia suficiente para dilucidar el proceso de transmisibilidad perinatal y los métodos de detección de SARS-CoV-2 relacionados con la lactancia materna y las divergencias entre los investigadores con respecto al establecimiento de la lactancia materna en casos de mujeres confirmadas o caso sospechoso de infección por COVID-19.

Conclusión: Equilibrando los beneficios comprobados para la madre y el niño mediante la práctica de la lactancia materna con los daños derivados de las manifestaciones de la infección por COVID-19, esta revisión señala un paquete de atención favorable al mantenimiento de la lactancia materna de lo que se conoce hasta ahora.

\section{Como citar:}

Tacla MT, Rossetto EG, Perdigão GM, Zani EM, Silva IV. Reflexões sobre o aleitamento materno em tempos de pandemia por COVID-19 Rev Soc Bras Enferm Ped. 2020;20(Especial COVID-19):60-76.

\footnotetext{
${ }^{1}$ Universidade Estadual de Londrina, Londrina, PR, Brasil.

Conflitos de interesse: nada a declarar.

Submetido: 24 de Julho de 2020 | Aceito: 18 de Setembro de 2020

Autor correspondente: Mauren Teresa Grubisich Mendes Tacla | E-mail: maurentacla@gmail.com

DOI: http://dx.doi.org/10.31508/1676-3793202000000127
}

\section{Descritores}

Aleitamento materno; Cronavirus; Infecções por coronavírus; COVID-19

Keywords

Breast feeding; Coronavirus; Coronavirus infections; COVID-19

\section{Descriptores}

Lactancia maternal; Coronavirus; Infecciones por coronavirus; COVID-19 


\section{Introdução}

A pandemia por COVID-19, declarada como tal pela Organização Mundial da Saúde (OMS) em 11 de março de 2020 e, atualmente em curso, tem afetado a população mundial em todas as faixas etárias, condições sociais e econômicas. Também as gestantes e puérperas são acometidas por esta doença, o que gera apreensão não só por suas vidas, mas também pelos riscos a que estão submetidos seus bebês. Ainda não há consenso quanto aos cuidados a serem tomados em alguns procedimentos que envolvem parturientes suspeitas ou com COVID-19, entre eles o processo de aleitamento materno (AM). ${ }^{(1)}$

A amamentação tem se consagrado como uma das práticas consideradas com melhor relação custo benefício para a saúde das crianças a curto e longo prazo. ${ }^{(2,3)}$ A despeito dessa evidência, foi desenvolvido um instrumento com a finalidade de mensurar o custo de não amamentar incluindo tempo de vida perdido, produtividade perdida e aumento do custo do Sistema de saúde. O montante de economia total estimado globalmente foi entre US\$257 e US\$341 bilhões anualmente. ${ }^{(4)}$

Em especial, neste cenário pandêmico, dentre as inúmeras vantagens do leite materno e sua superioridade frente a qualquer outro tipo de leite, é importante destacar sua capacidade imunomoduladora, desejável em qualquer situação. A amamentação precoce e duradoura fornece prevenção vital durante epidemias virais, devido ao alto valor do colostro e do leite materno e ao papel específico da lactoferrina, visto que, em conjunto, demonstram potenciais efeitos antivirais. Os níveis de lactoferrina no leite materno diminuem com o tempo e os bebês prematuros podem receber as maiores concentrações por períodos mais longos, o que pode reduzir o alto risco de sepse dos tratos intestinal e respiratório. ${ }^{(5)}$

Entretanto, esse consenso global favorável à prática do $\mathrm{AM} \mathrm{e}$, consequentemente à continuidade de todos os esforços necessários para a sua promoção tem sido muitas vezes ameaçado pelas pesquisas realizadas pelo mundo todo e publicadas a cada momento e consequentemente, pelas próprias entidades/órgãos governamentais, sociedades de especialidades e associações de classe quando se veem diante de novos achados e da necessidade de adoção de algumas medi- das de segurança para a prevenção e controle da infecção neonatal em tempos de pandemia por COVID-19.

O Centers for Disease Control and Prevention (CDC), embora admita que o cenário ideal para o cuidado do recém-nascido ( $R N)$ a termo saudável seja junto à sua mãe, recomenda fortemente que deve ser considerada a separação temporária de ambos caso a puérpera seja COVID-19 confirmado ou suspeito com a justificativa de reduzir o risco de transmissão ao neonato. ${ }^{(6)}$ Mesmo reconhecendo que os dados disponíveis sugerem que seja improvável a transmissão do vírus pelo leite materno, o CDC adverte que amamentar deve ser determinado pela mulher em conjunto com sua família e profissionais de saúde.(7)

A separação entre mãe e RN em momentos tão cruciais para o estabelecimento da amamentação pode ameaçar o sucesso do AM que aprimora a saúde da mãe e das crianças, implicando em benefícios duradouros para a família, que resultam em um impacto social e econômico significativo. ${ }^{(8)}$ Parece, no mínimo, contraditório incentivar práticas que possam desestimular a amamentação num momento crítico de pandemia em que devemos buscar meios e estratégias que minimizem todo tipo de prejuízo, os quais já não são poucos neste contexto.

A pandemia atual é uma excelente oportunidade para educar o público sobre os benefícios do leite humano e defender a amamentação, mas principalmente reconhecer tal prática como uma importante intervenção que salva vidas.(9) Neste contexto, um grupo de pesquisadores têm alertado para os prejuízos e consequências advindos dos desmontes e colapsos dos serviços de saúde resultantes da falta de assertividade nas tomadas de decisões apontando um risco de aumento devastador de mortes maternas e crianças abaixo de 5 anos. ${ }^{(10)}$ Esses pesquisadores utilizaram o Lived Saved Tool para estimar o número de mortes adicionais em três cenários hipoteticamente desenvolvidos a partir de possibilidades reais da pandemia por COVID-19. Na melhor das hipóteses, estimaram 253.500 mortes adicionais de crianças abaixo de 5 anos e 12.200 mortes maternas adicionais em um período de 6 meses resultantes da pandemia em 118 países de baixa e média renda. ${ }^{(10)}$

Neste sentido, não faltam recomendações relacionadas aos cuidados com a mãe e o bebê na vigência da pandemia por COVID-19, mas há necessidade de 
fundamentá-las com vistas a superar o desafio de contrabalançar os riscos e benefícios para a tomada de decisão pelas práticas que promovam o bem no presente momento, sem comprometer os meses subsequentes. Assim sendo, foi elaborada a seguinte pergunta de pesquisa: Quais são as evidências disponíveis relacionadas ao aleitamento materno em tempos de pandemia por COVID-19? Esta revisão, portanto, tem como objetivo prover uma reflexão sobre as evidências científicas publicadas na literatura relacionadas com o aleitamento materno em tempos de pandemia por COVID-19.

\section{Métodos}

Trata-se de uma revisão de escopo, a qual atende a necessidade de explorar um tema de particular interesse por meio de um mapeamento das evidências disponíveis, apontando os delineamentos de estudos publicados e identificando as lacunas de conhecimento no meio científico. Esse tipo de revisão é indicado particularmente para quaisquer eventos de saúde emergentes que requeiram uma visão geral das evidências publicadas, sem o compromisso de avaliar qualitativamente o rigor dos delineamentos de estudos ou mesmo selecionar tipos de estudos específicos para responder aos anseios da pesquisa. ${ }^{(11)} \mathrm{A}$ revisão de escopo também é considerada um tipo de revisão sistemática e deve seguir o rigor de um protocolo de procedimentos.

O protocolo norteador para o desenvolvimento das etapas seguidas nesta revisão foi o PRISMA-ScR ${ }^{(11)}$ que embasa revisões sistemáticas, meta-análises e publicou uma extensão desse checklist especificamente para revisões de escopo: 1) Alinhamento da pergunta de pesquisa com o objetivo; 2) Busca dos estudos relevantes (critérios de inclusão, exclusão, definição dos termos); 3) Seleção dos estudos e extração dos dados; 4) Análise e registro das evidências; 5) Síntese e descrição das evidências; 6) Análise e conclusão dos achados. Para a elaboração da pergunta de pesquisa "Quais as evidências disponíveis relacionadas ao aleitamento materno em tempos de pandemia por COVID-19?", foi utilizado o acrônimo adaptado para revisões de escopo $\mathrm{P}$ (população), $\mathrm{C}$ (conceito) e $\mathrm{C}$ (contexto), na qual a população $(\mathrm{P})$ abrangia os recém-nascidos, as gestantes, puérperas, leite humano, lactentes, lactantes; o conceito $(\mathrm{C})$ diz respeito às evidências relacionadas ao aleitamento materno e o contexto (C), a pandemia por COVID-19.

A busca dos estudos foi realizada considerando estudos de janeiro a 15 de julho de 2020 nas bases de dados: The National Library of Medicine (MEDLINE/ PubMed), Current Nursing and Allied Health Literature (CINAHL), BDENF, Scopus and LILACS. Os descritores cadastrados no DeCS (Descriptors in Health Science) e no MeSH (Medical Subject Headings) bem como as palavras-chave (keywords) não localizadas como descritores controlados foram combinados entre si para a formulação das estratégias de busca (Figura 1). ${ }^{(12)}$ Todas as publicações em inglês, português ou espanhol em periódico que procurasse fundamentar as práticas de AM em tempos de COVID-19 (comunicação, perspectiva, consensos, relato de caso, texto científico ou acadêmico etc.) foram incluídas. Foram excluídos artigos repetidos, documentos técnicos publicados em outras fontes que não periódicos científicos, bem como cartas, editorial ou opinião de especialista, estudos publicados em outra língua que não as três línguas mencionadas, aqueles que não respondiam à pergunta de pesquisa ou que não foi possível acessar o documento completo.

Depois das etapas 1 e 2 , dois pesquisadores fizeram as buscas independentes nas bases selecionadas. Mediante leitura dos títulos e resumos, selecionaram os estudos. Na sequência dessas etapas, um terceiro pesquisador investigou as referências dos estudos selecionados, bem como as referências de estudos de revisão que não foram incluídos a fim de encontrar outros estudos elegíveis que porventura não tinham sido localizados até então. Após a seleção foram agrupados em três quadros temáticos (Quadros 1, 2 e 3) constando título, periódico de publicação, país de origem, data e, delineamento de estudo, método e principais resultados. Também foram consultados documentos publicados nos websites do CDC, da OMS, Sociedade Brasileira de Enfermeiros Pediatras (SOBEP) e da Sociedade Brasileira de Pediatria (SBP), que subsidiaram as decisões das etapas 5 e 6 da revisão, porém esses documentos não foram incluídos na seleção. Para as fases 5 e 6, dois pesquisadores mais experientes na área fizeram a leitura na íntegra de todos os estudos selecionados e discutiram as dúvidas e divergências com vistas a responder à 
pergunta de pesquisa e finalização do artigo, conforme descrito no diagrama da figura $1^{(12)}$

Por se tratar de um estudo de revisão, foi assegurada a confiabilidade e fidelidade das informações contidas nos artigos. Esses aspectos foram garantidos pelos cuidados de rigor e adequada citação no tratamento e apresentação dos resultados encontrados. Esta revisão não foi registrada.

\section{Resultados}

O montante de publicações relacionados com a temática é um reflexo da preocupação mundial com a realidade da pandemia na atualidade. De mais de $20 \mathrm{mil}$ publicações identificadas, foram selecionados 59 artigos mediante análise dos títulos e resumos, considerando os critérios de elegibilidade. Depois da leitura na íntegra, 31 foram excluídos, pelos seguintes motivos: não abordarem a temática investigada $(\mathrm{n}=15)$; serem duplicados $(\mathrm{n}=9)$; por se tratarem de cartas, editoriais ou opinião $(n=5)$; e não estarem disponíveis na íntegra $(n=2)$. Assim sendo, foram incluídos 28 estudos que constituíram a amostra final desta revisão (Figura 1). ${ }^{(12)}$ As publicações são oriundas, em sua maior parte, da China ( $\mathrm{n}=8)$, dos Estados Unidos da América (EUA) $(n=7)$ e da Itália $(n=4)$, países altamente atingidos pela atual pandemia, entre outros países como a Espanha, Brasil, Singapura, Austrália, Croácia, Polônia e Irã.

Em geral, nem sempre os estudos selecionados tratavam especificamente sobre AM, foco desta revisão, mas para os quadros sínteses foram extraídas apenas as questões diretamente relacionadas ao tema de interesse. No quadro 1 são apresentados 08 estudos que versam sobre transmissibilidade e detecção do vírus SARS-CoV-2 relacionados ao AM. O quadro 2 reúne 12 artigos que discutem sobre as recomendações relacionadas com o cuidado perinatal. No quadro 3 é apresentada uma síntese das revisões sistematizadas selecionadas $(n=8)$, contendo os principais resultados que interferem sobre a prática do AM. Em todos os quadros as publicações estão apresentadas cronologicamente, das mais atuais para as mais antigas. Algumas revisões que também poderiam apresentar recomendações sobre AM, podem não ter sido incluídas porque não foram identificadas pela estratégia de busca utilizada. ${ }^{(13-39)}$

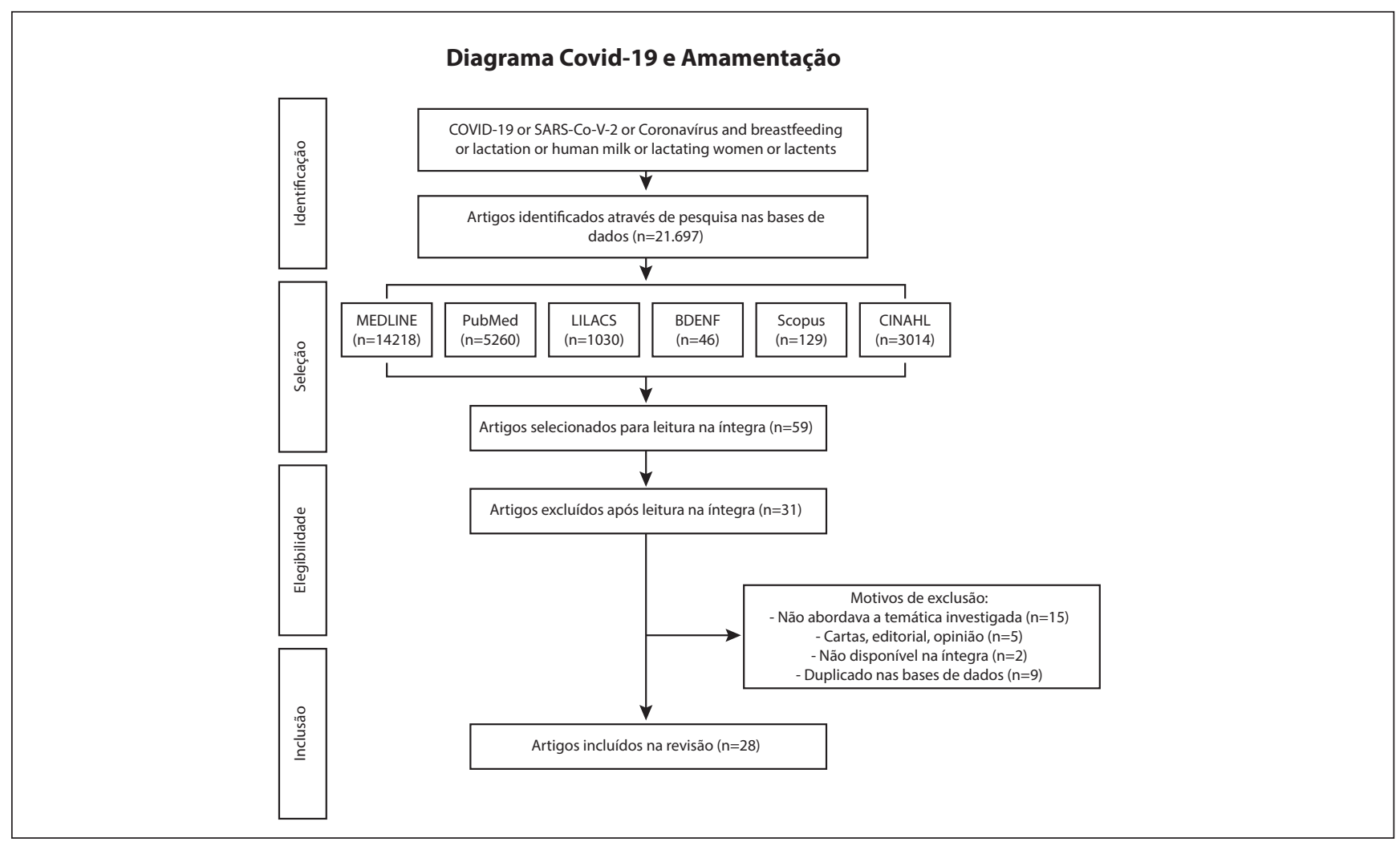

Fonte: Aromataris E, Munn Z (Editors). JBI Manual for Evidence Synthesis. JBI, 2020. Available from https://synthesismanual.jbi.global. ${ }^{(12)}$

Figura 1. Diagrama de identificação e seleção de artigos para revisão sobre COVID-19 e aleitamento materno 


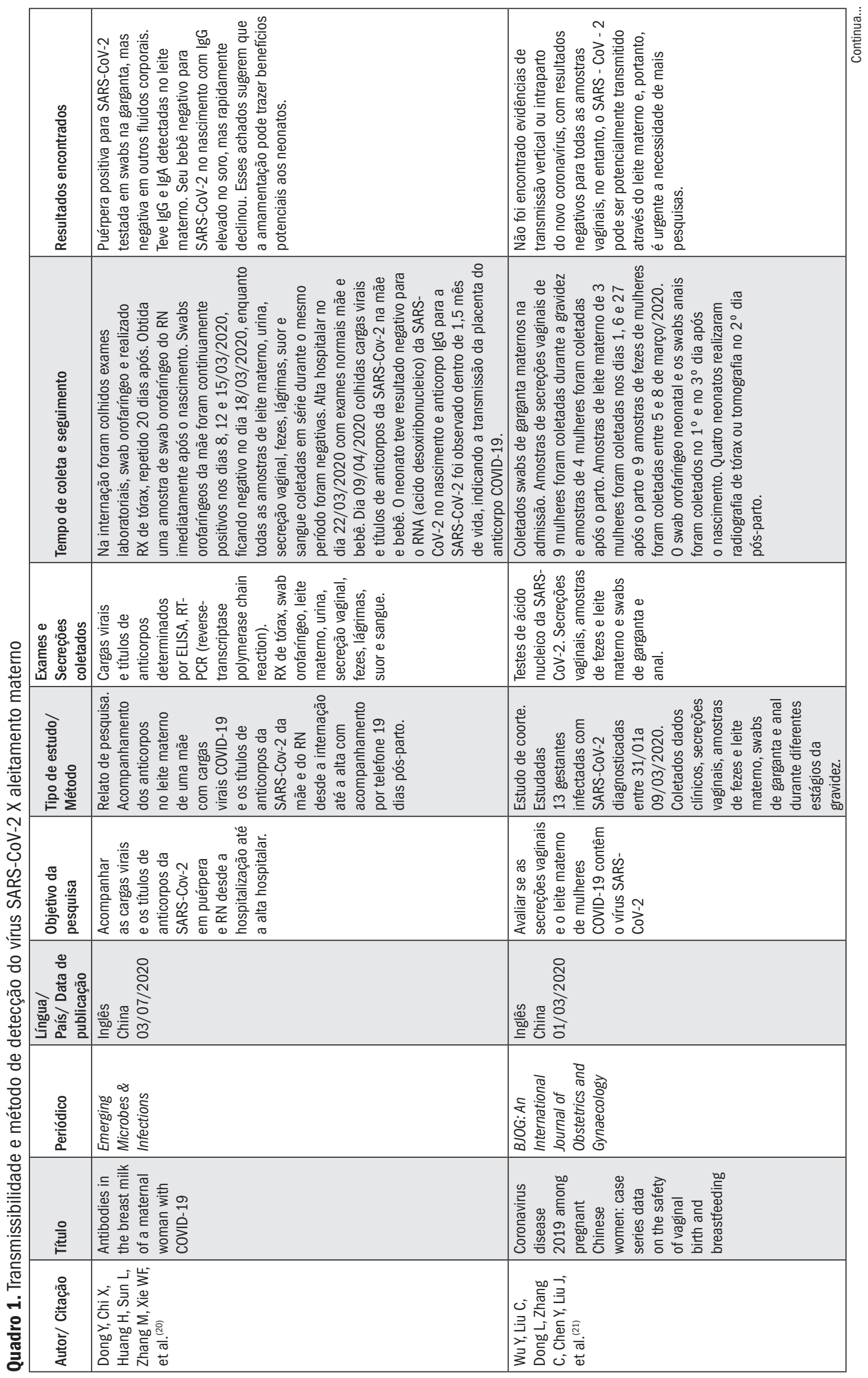




\begin{tabular}{|c|c|c|}
\hline 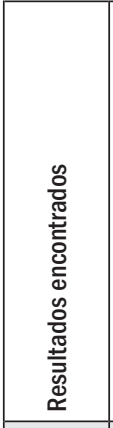 & 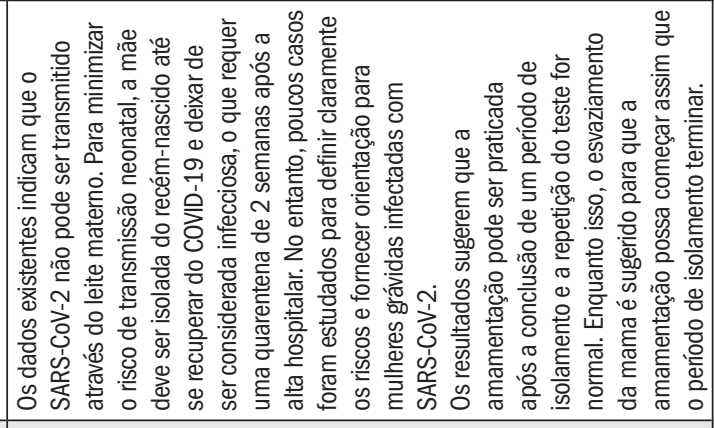 & 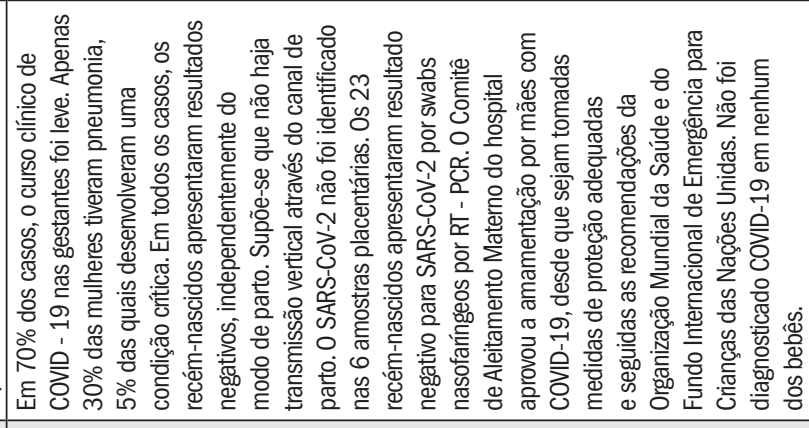 \\
\hline 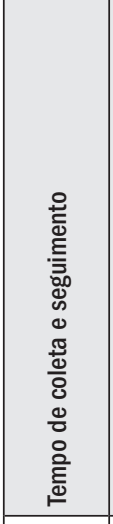 & 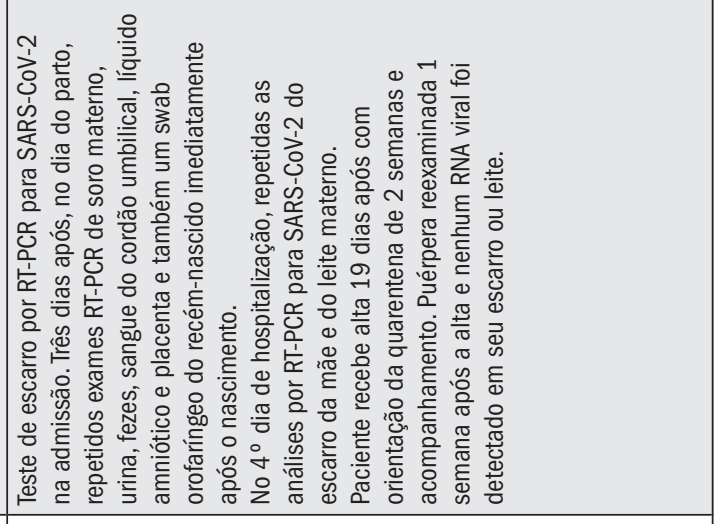 & 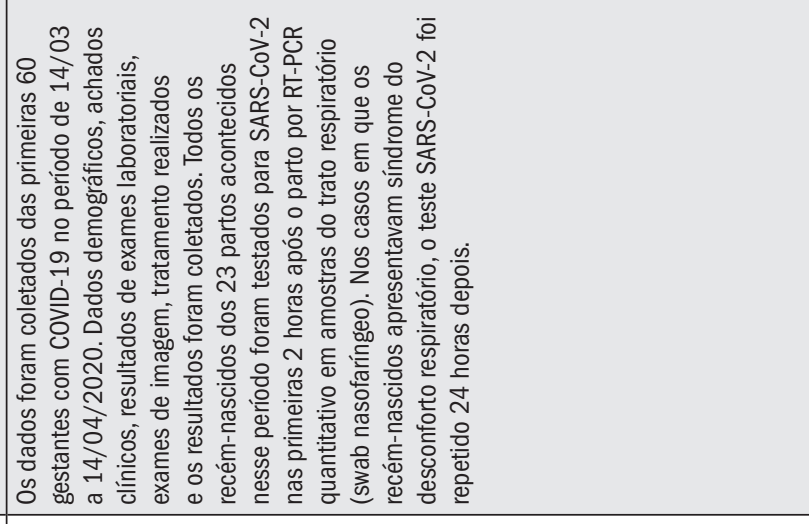 \\
\hline 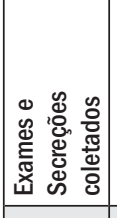 & 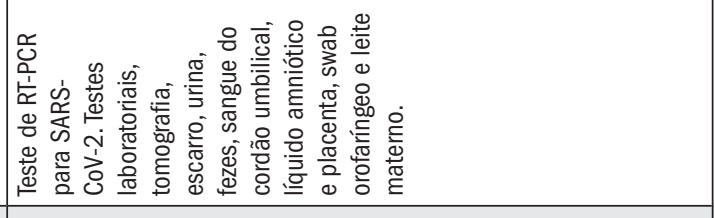 & 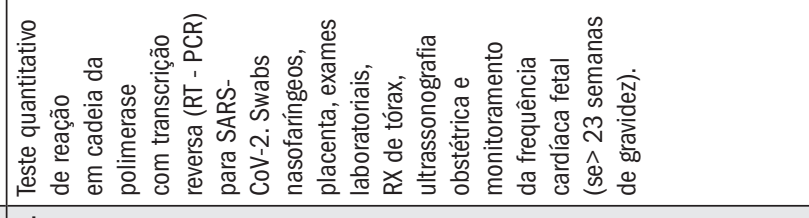 \\
\hline 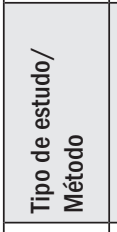 & 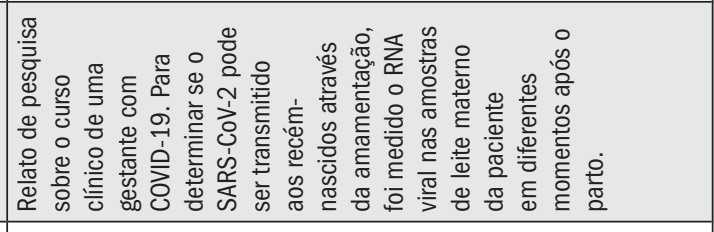 & 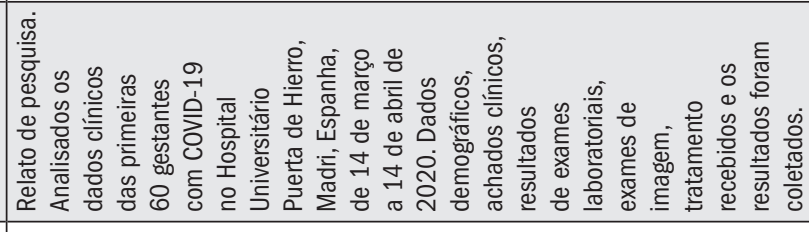 \\
\hline 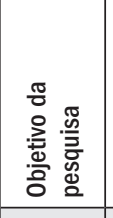 & 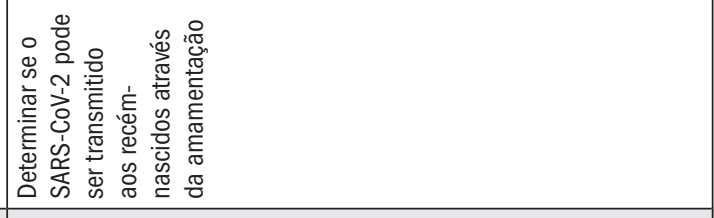 & 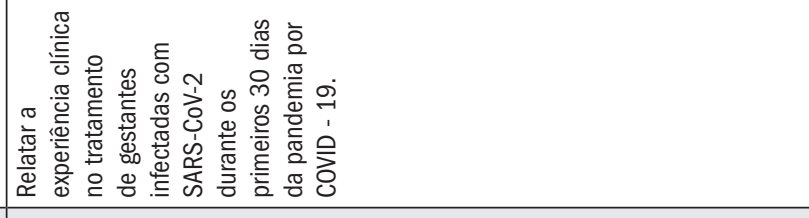 \\
\hline 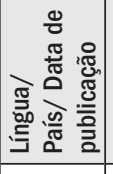 & 党 & 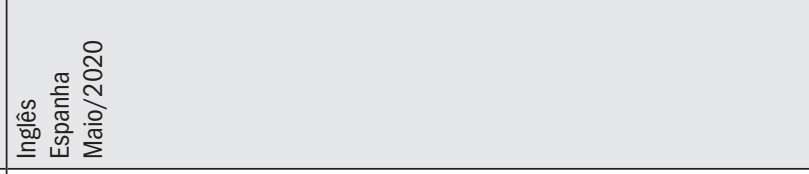 \\
\hline 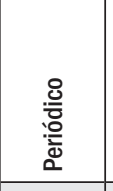 & 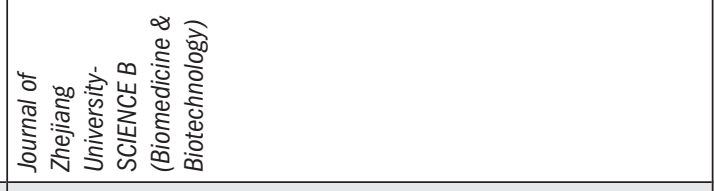 & 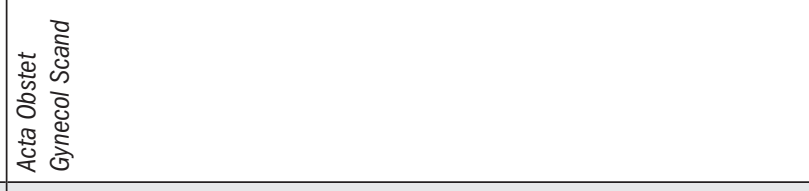 \\
\hline 总 & 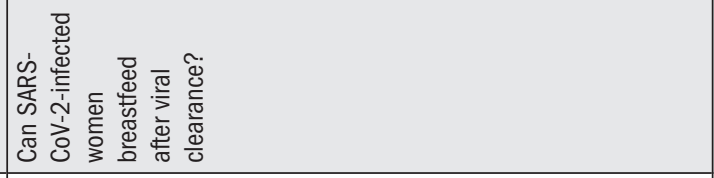 & 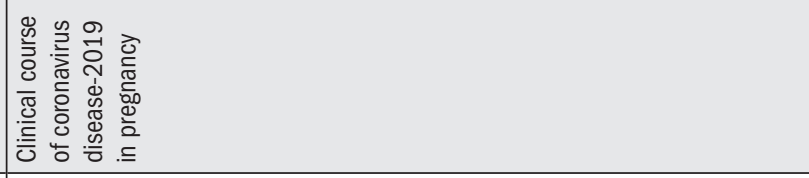 \\
\hline 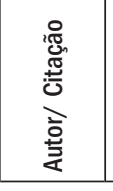 & 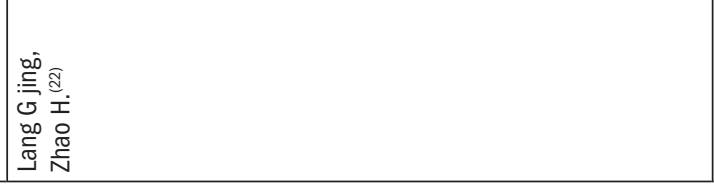 & 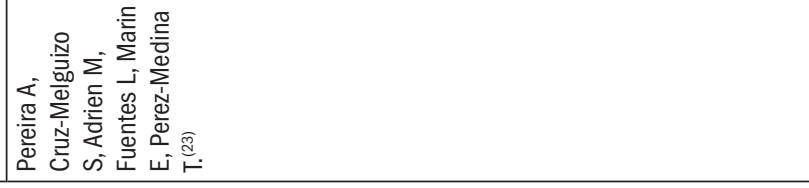 \\
\hline
\end{tabular}




\begin{tabular}{|c|c|c|}
\hline 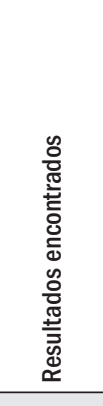 & 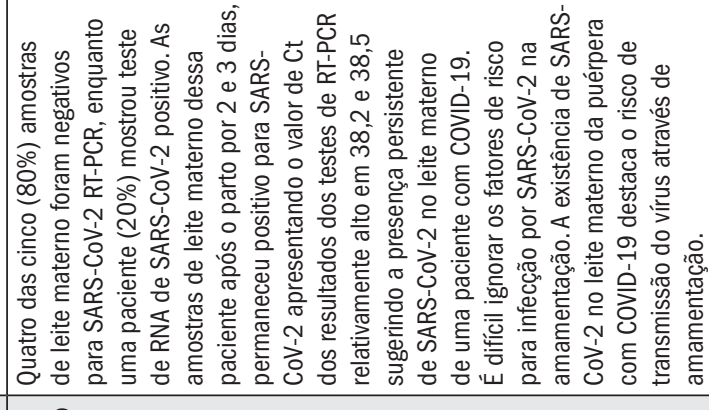 & 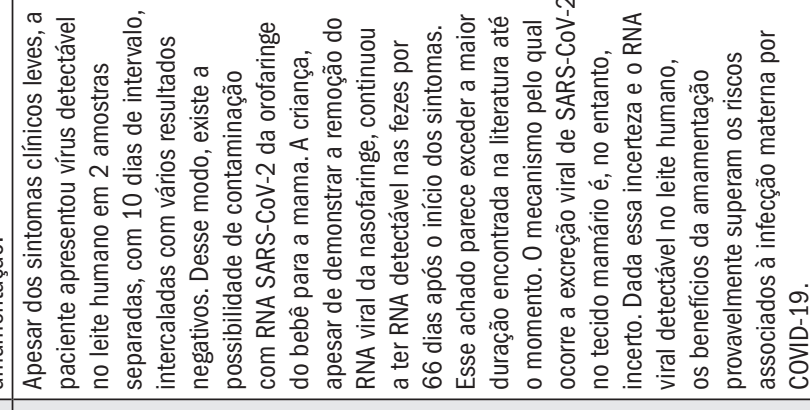 \\
\hline 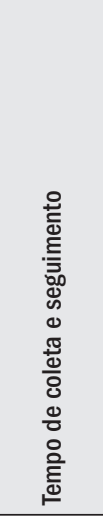 & 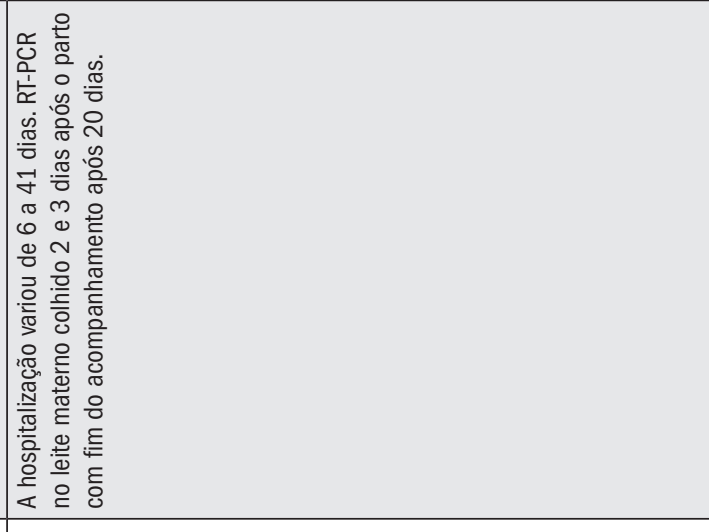 & 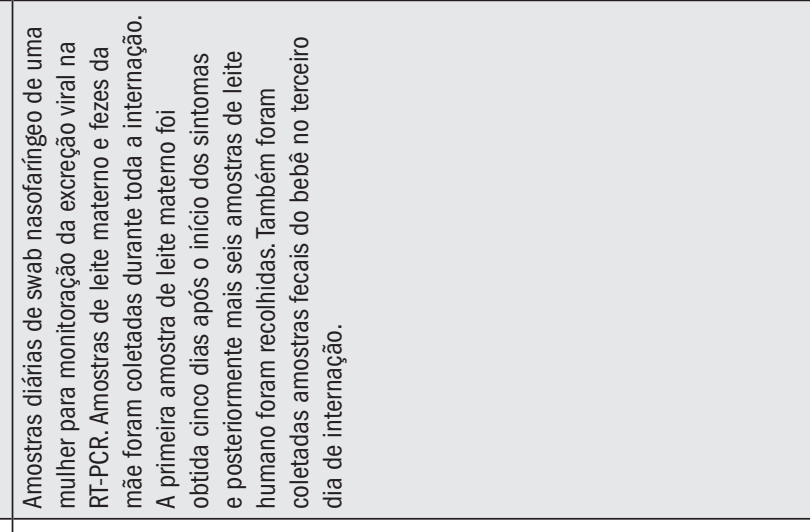 \\
\hline 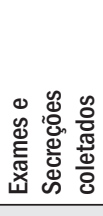 & 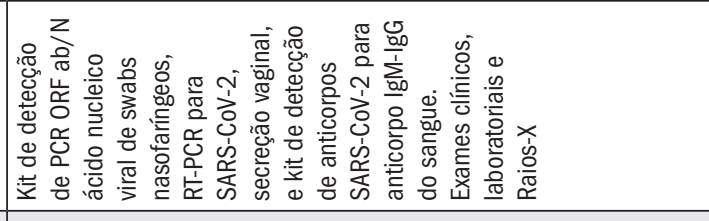 & 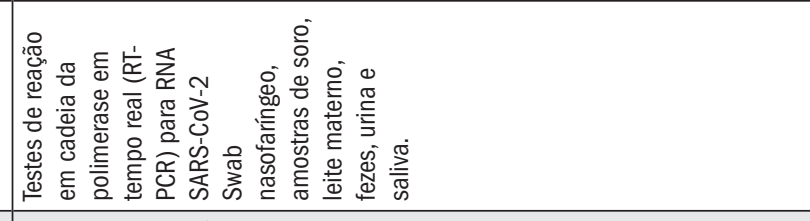 \\
\hline 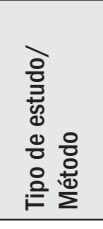 & 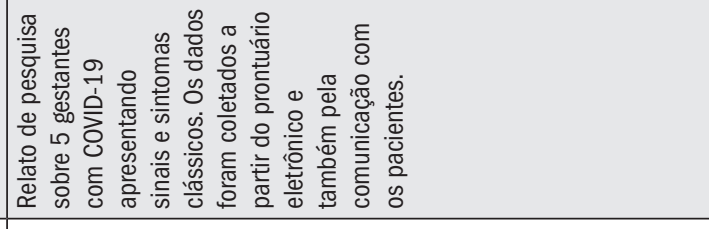 & 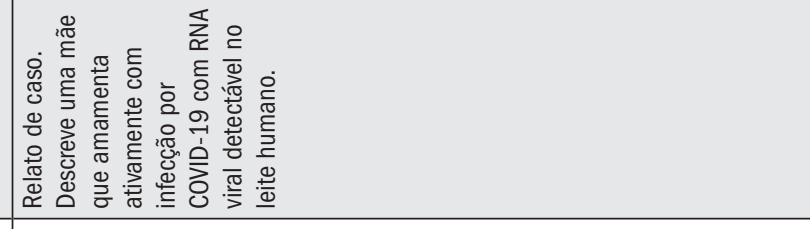 \\
\hline 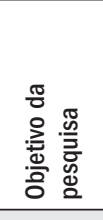 & 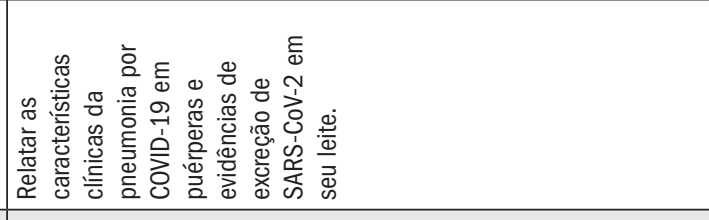 & 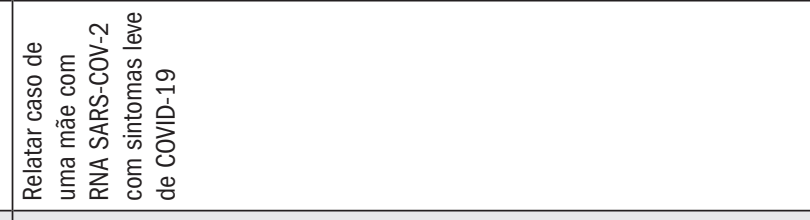 \\
\hline 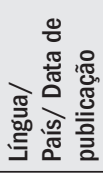 & 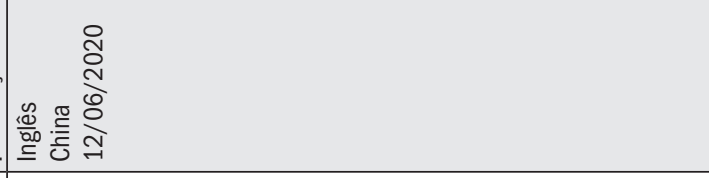 & 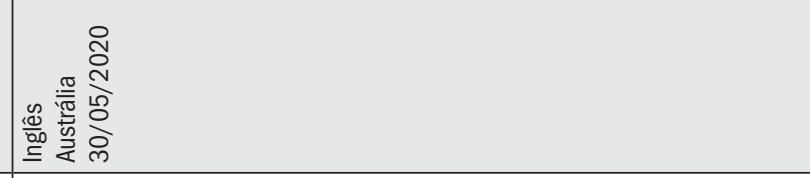 \\
\hline 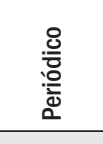 & 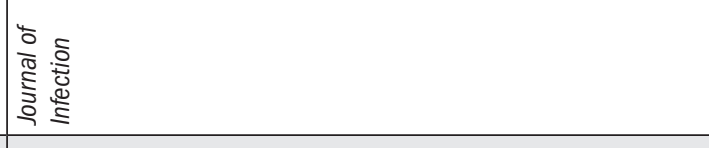 & 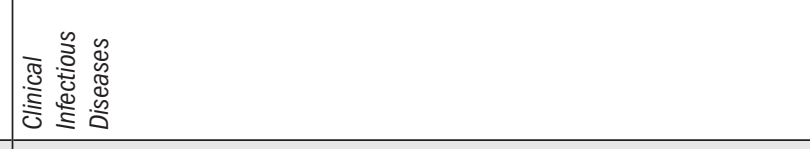 \\
\hline 旁 & 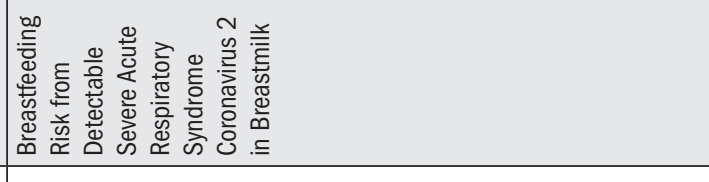 & 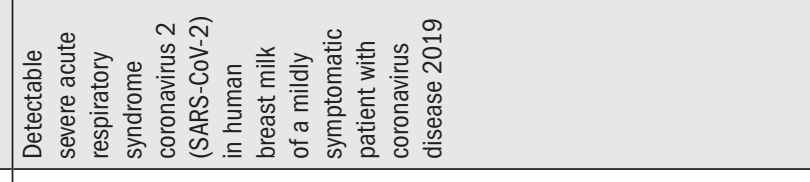 \\
\hline 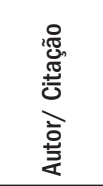 & 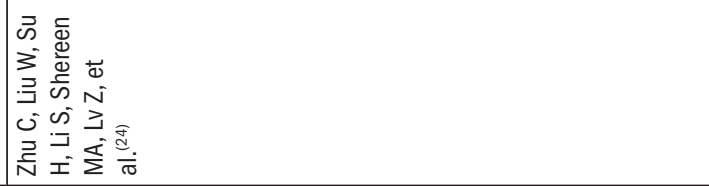 & 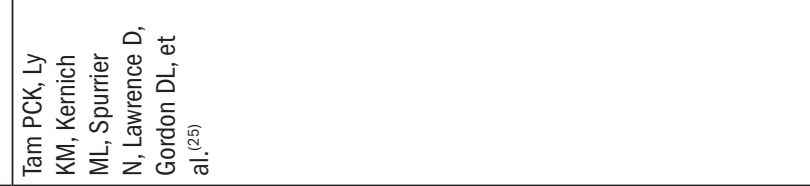 \\
\hline
\end{tabular}




\begin{tabular}{|c|c|c|}
\hline 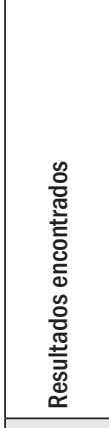 & 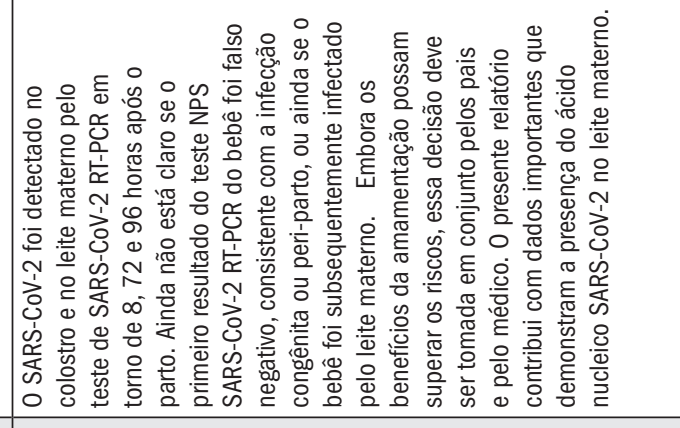 & 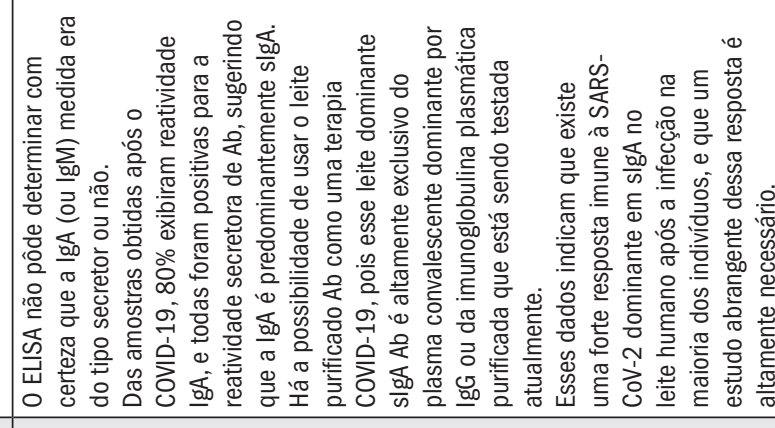 \\
\hline 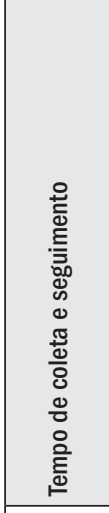 & 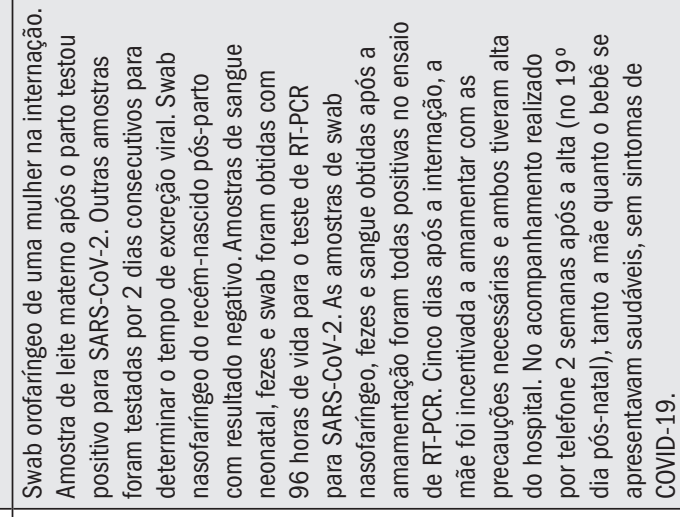 & 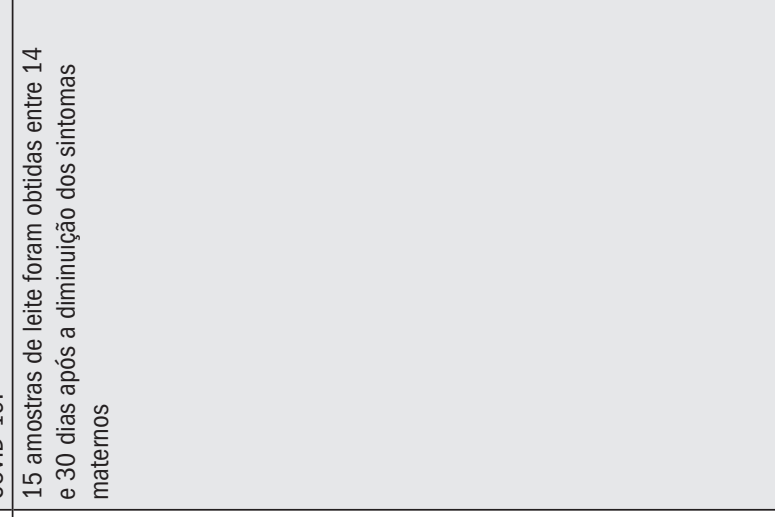 \\
\hline 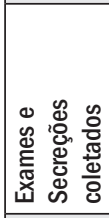 & 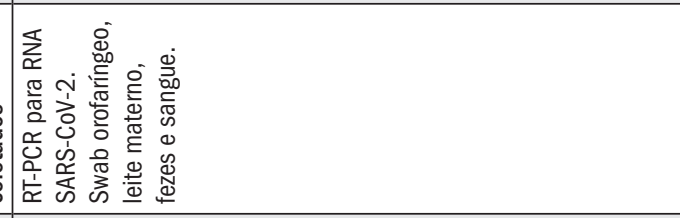 & 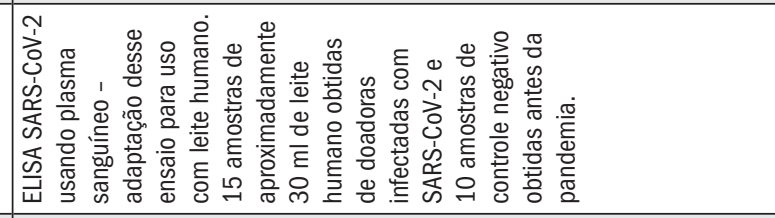 \\
\hline 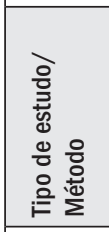 & 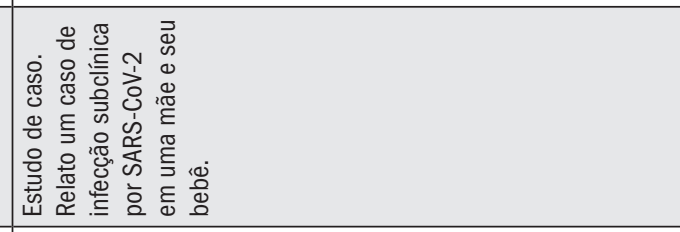 & 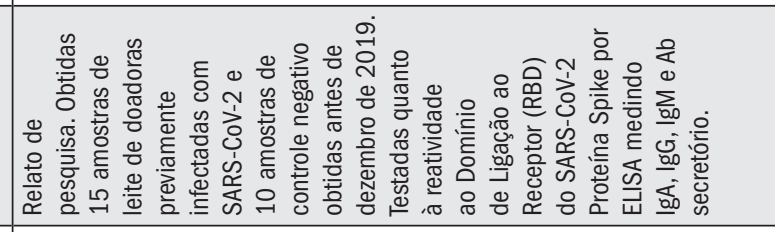 \\
\hline 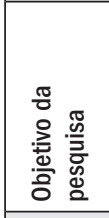 & 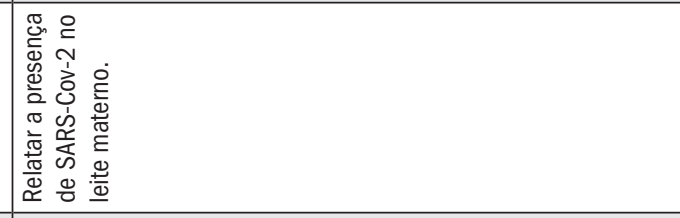 & 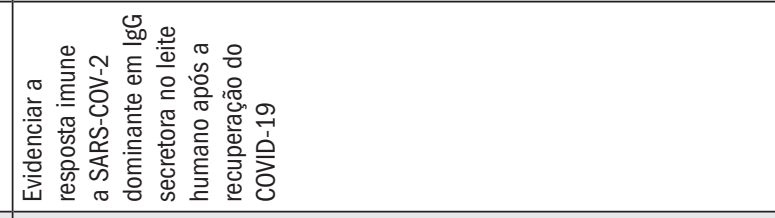 \\
\hline 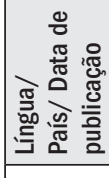 & : & 畩 \\
\hline 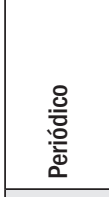 & 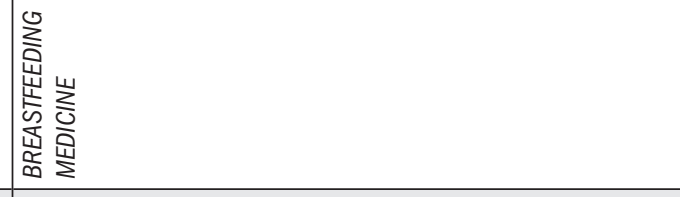 & 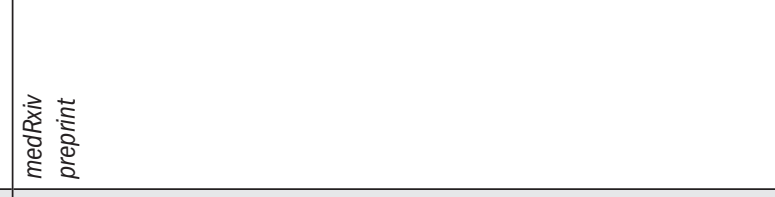 \\
\hline 㱏 & 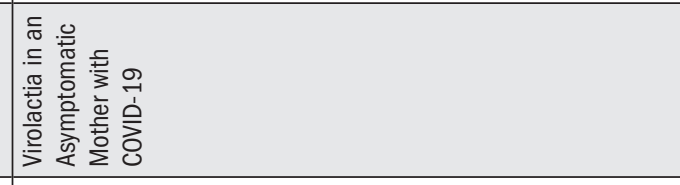 & 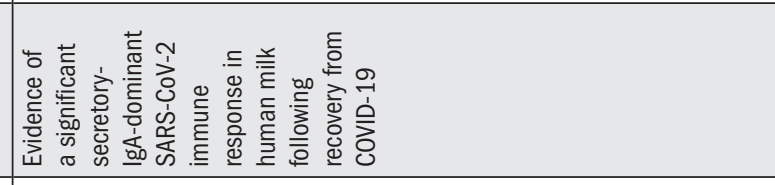 \\
\hline 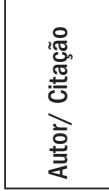 & 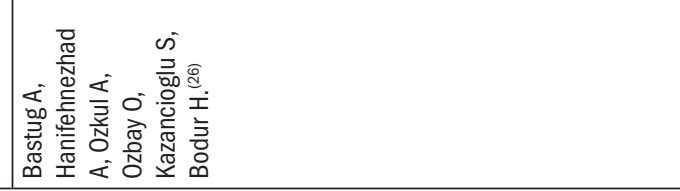 & 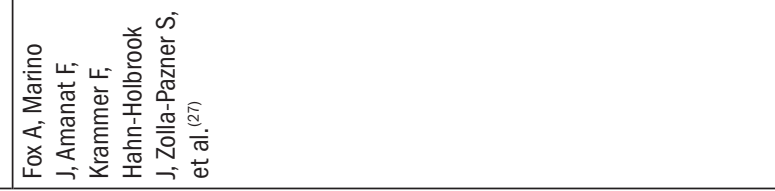 \\
\hline
\end{tabular}


Quadro 2. Síntese dos artigos que reuniram recomendações sobre aleitamento materno e COVID-19

\begin{tabular}{|c|c|c|c|c|}
\hline Autor/ Citação & Título & Periódico & \begin{tabular}{|l} 
Periódico \\
Língua \\
País \\
Data da \\
publicação
\end{tabular} & Recomendações \\
\hline Stanojević M. ${ }^{(1)}$ & $\begin{array}{l}\text { Are COVID-19-positive mothers } \\
\text { dangerous for their term and well } \\
\text { newborn babies? Is there an answer? }\end{array}$ & J. Perinat. Med. & $\begin{array}{l}\text { Inglês } \\
\text { Croácia } \\
\text { 13/05/2020 }\end{array}$ & $\begin{array}{l}\text { A recomendação é de que a mulher infectada assintomática } \\
\text { ou não deve decidir sobre a amamentação, bem como sobre } \\
\text { o contato pele a pele logo ao nascimento. Mas em algumas } \\
\text { situações, o leite fresco extraído é a primeira escolha, } \\
\text { preferencialmente à amamentação direta na mãe. Isso a } \\
\text { depender da situação epidemiológica da região e da gravidade } \\
\text { da doença da mãe. }\end{array}$ \\
\hline $\begin{array}{l}\text { Davanzo R, Moro G, } \\
\text { Sandri F, Agosti M, } \\
\text { Moretti C, Mosca F. }\end{array}$ & $\begin{array}{l}\text { Breastfeeding and coronavirus } \\
\text { disease-2019 Ad interim indications } \\
\text { of the Italian Society of Neonatology } \\
\text { endorsed by the Union of European } \\
\text { Neonatal \& Perinatal Societies }\end{array}$ & $\begin{array}{l}\text { Maternal and } \\
\text { Child Nutrition }\end{array}$ & $\begin{array}{l}\text { Inglês } \\
\text { Itália } \\
\text { 30/03/2020 }\end{array}$ & $\begin{array}{l}\text { Se uma mãe previamente identificada como COVID-19 positiva } \\
\text { ou sob investigação para COVID-19 for assintomática } \\
\text { ou paucissintomática no momento do parto, } \\
\text { acomodação conjunta é viável e a amamentação direta é } \\
\text { aconselhável,sob medidas estritas de controle de } \\
\text { infecção. Diferentemente, quandouma mãe com COVID-19 está } \\
\text { doente demais para cuidar do recém-nascido, } \\
\text { ele será tratado separadamente e alimentado com leite } \\
\text { materno fresco extraído, sem pasteurizá-lo, pois não se } \\
\text { acredita que o leite humano seja um veículo do COVID-19. }\end{array}$ \\
\hline $\begin{array}{l}\text { Rasmussen SA, } \\
\text { Jamieson DJ.(8) }\end{array}$ & $\begin{array}{l}\text { Coronavirus Disease } 2019 \text { (COVID-19) } \\
\text { and pregnancy } \\
\text { Responding to a Rapidly Evolving } \\
\text { Situation }\end{array}$ & $\begin{array}{l}\text { Obstetrics \& } \\
\text { Gynecology }\end{array}$ & $\begin{array}{l}\text { Inglês } \\
\text { Georgia } \\
25 / 06 / 2020\end{array}$ & $\begin{array}{l}\text { Gestantes que chegam para o parto precisam ser estratificadas } \\
\text { de acordo com os critérios locais em baixa, médio ou alto } \\
\text { risco para infecção por COVID-19, e assim determinar a } \\
\text { disposição da paciente, as medidas de controle e precaução. } \\
0 \text { aleitamento materno não está contraindicado, mas se a } \\
\text { paciente decidir amamentar, ela deve usar máscara e assim } \\
\text { reduzir o risco de transmissão por gotículas respiratórias. }\end{array}$ \\
\hline $\begin{array}{l}\text { Giuliani C, Li Volsi P, } \\
\text { Brun E, Chiambretti } \\
\text { A, Giandalia A, Tonutti } \\
\text { L, et al. }{ }^{\left({ }^{9}\right)}\end{array}$ & $\begin{array}{l}\text { Breastfeeding during the COVID-19 } \\
\text { pandemic: Suggestions on behalf of } \\
\text { woman study group } \\
\text { of AMD }\end{array}$ & $\begin{array}{l}\text { Diabetes } \\
\text { Research and } \\
\text { Clinical Practice }\end{array}$ & $\begin{array}{l}\text { Inglês } \\
\text { Itália } \\
30 / 05 / 2020\end{array}$ & $\begin{array}{l}\text { De acordo com a OMS, UNICEF, ISS (Istituto Superiore di } \\
\text { Sanita), IUOG (International Society of Ultrasound in Obstetrics } \\
\text { and Gynecology), RCOG (Royal College of Obstetricians and } \\
\text { Gynaecologists), CDC (Disease Control and Prevention), ABM } \\
\text { (Academy of Breastfeeding Medicine) e FIGO (Federação } \\
\text { Internacional das Sociedades de Ginecologia e Obstetrícia) e, } \\
\text { em particular, com o SIN (Italian Society of Neonatology), a } \\
\text { UENPS (Union of European Neonatal \& Perinatal Societies) e o } \\
\text { Ministério da Saúde italiano recomendam o manejo conjunto } \\
\text { da mãe e do recém-nascido, a fim de facilitar a interação e o } \\
\text { início da amamentação. } \\
\text { A decisão de separar ou não a mãe e o recém-nascido deve } \\
\text { ser individualizada, levando em consideração o consentimento } \\
\text { das informações dos pais, o bom estado de saúde da mãe e } \\
\text { do recém-nascido e a capacidade de cuidar do recém-nascido. } \\
\text { Sugestões para as mães com diabetes: A dose de insulina deve } \\
\text { ser cuidadosamente avaliada em mulheres que amamentam. }\end{array}$ \\
\hline $\begin{array}{l}\text { Moro GE, Bertino } \\
\text { E. }^{(10)}\end{array}$ & $\begin{array}{l}\text { Breastfeeding, Human Milk Collection } \\
\text { and Containers, and Human Milk } \\
\text { Banking: Hot Topics During the } \\
\text { COVID-19 Pandemic }\end{array}$ & $\begin{array}{l}\text { Journal of Human } \\
\text { Lactation }\end{array}$ & $\begin{array}{l}\text { Inglês } \\
\text { Itália } \\
26 / 05 / 2020\end{array}$ & $\begin{array}{l}\text { Quando possível, o AM deve ser promovido e apoiado sem } \\
\text { desconsiderar a opção de extração do leite materno. } \\
\text { - Superfícies externa dos recipientes contendo leite humano } \\
\text { podem estar contaminadas pelo SARS-CoV-2. Protocolos } \\
\text { preparados de acordo com sistemas de Análise de Risco } \\
\text { e Controle de Pontos Críticos deveriam ser utilizados para } \\
\text { assegurar o controle dos recipientes. } \text { Os bancos de leite } \\
\text { humano deveriam instalar um controle específico de } \\
\text { positividade para COVID-19 nas mulheres doadoras durante } \\
\text { esse período crítico. } \cdot 0 \text { volume reduzido de leite humano } \\
\text { disponível nos bancos de leite humano deveria ser alocado } \\
\text { como risco maior para os bebês prematuros. }\end{array}$ \\
\hline $\begin{array}{l}\text { Tomori C, Gribble } \\
\text { K, Palmquist AEL, } \\
\text { Ververs M, Gross } \\
\text { MS. }{ }^{(13)}\end{array}$ & $\begin{array}{l}\text { When Separation is not the Answer: } \\
\text { Breastfeeding Mothers and Infants } \\
\text { affected by COVID-19 }\end{array}$ & $\begin{array}{l}\text { Maternal \& Child } \\
\text { Nutrition }\end{array}$ & $\begin{array}{l}\text { Inglês } \\
\text { EUA } \\
26 / 05 / 2020\end{array}$ & $\begin{array}{l}\text { Os serviços de saúde devem considerar os impactos a curto } \\
\text { e longo prazo da separação de mães e bebês em suas } \\
\text { políticas. Separando todas as díades mãe-bebê com suspeita } \\
\text { ou confirmação positiva de SARS-CoV-2 independentemente } \\
\text { da gravidade da doença, pode levar a uma constelação de } \\
\text { doenças e mortes evitáveis entre bebês e mulheres em todo o } \\
\text { mundo. }\end{array}$ \\
\hline
\end{tabular}


Continuação.

\begin{tabular}{|c|c|c|c|c|}
\hline Autor/ Citação & Título & Periódico & $\begin{array}{l}\text { Periódico } \\
\text { Língua } \\
\text { País } \\
\text { Data da } \\
\text { publicação }\end{array}$ & Recomendações \\
\hline $\begin{array}{l}\text { Rajewska A, } \\
\text { Mikołajek-Bedner } \\
\text { W, Lebdowicz-Knul } \\
\text { J, Sokołowska M, } \\
\text { Kwiatkowski S, Torbé } \\
\text { A. }{ }^{(14)}\end{array}$ & $\begin{array}{l}\text { COVID-19 and pregnancy - where are } \\
\text { we now? A review }\end{array}$ & J. Perinat. Med & $\begin{array}{l}\text { Inglês } \\
\text { Polônia } \\
11 / 05 / 2020\end{array}$ & $\begin{array}{l}\text { Coronavirus ainda não foi encontrado no leite materno de } \\
\text { mulheres infectadas até agora, portanto, recomenda-se } \\
\text { manter o AM ou, pelo menos oferecer leite materno extraído } \\
\text { na mamadeira por uma outra pessoa saudável tomando as } \\
\text { devidas precauções. Se a mãe for assintomática ou levemente } \\
\text { afetada pela infecção por coronavirus, a mãe deve usar } \\
\text { máscara e tomar cuidados apropriados de lavagem das mãos. }\end{array}$ \\
\hline $\begin{array}{l}\text { Marinelli KA, } \\
\text { Lawrence RM. }^{(15)}\end{array}$ & $\begin{array}{l}\text { Safe Handling of Containers of } \\
\text { Expressed Human Milk in all Settings } \\
\text { During the } \\
\text { SARS-CoV-2 (COVID-19) Pandemic }\end{array}$ & $\begin{array}{l}\text { Journal of Human } \\
\text { Lactation }\end{array}$ & $\begin{array}{l}\text { Inglês } \\
\text { EUA } \\
25 / 03 / 2020\end{array}$ & $\begin{array}{l}\text { Receber recipientes de leite dos doadores com as mãos } \\
\text { enluvadas; Limpar a superfície externa dos recipientes } \\
\text { individuais com desinfetante, alternativamente, use } \\
\text { “desinfecção de alto nível”; Coloque os recipientes limpos para } \\
\text { secar antes de guardar em refrigeradores; Para unidades de } \\
\text { internação, recomenda-se caixas separadas para cada bebê na } \\
\text { mesma geladeira desde que os recipientes tenham sido limpos } \\
\text { previamente. } \\
\text { Durante a extração do leite, para doação ou não, as mães } \\
\text { devem fazer uso de máscaras respiratórias e empregar boas } \\
\text { práticas de lavagem das mãos antes e depois da extração. }\end{array}$ \\
\hline $\begin{array}{l}\text { Dashraath P, Wong } \\
\text { JU, Lim MXK, Lim } \\
\text { LM, Li S, Biswas A, } \\
\text { et al. }{ }^{(16)}\end{array}$ & $\begin{array}{l}\text { Coronavirus disease } 2019 \text { (COVID-19) } \\
\text { pandemic and pregnancy }\end{array}$ & $\begin{array}{l}\text { AJOG: American } \\
\text { Journal of } \\
\text { Obstetrics \& } \\
\text { Gynecology }\end{array}$ & $\begin{array}{l}\text { Inglês } \\
\text { Singapura } \\
17 / 03 / 2020\end{array}$ & $\begin{array}{l}\text { As mulheres grávidas representam um grupo exclusivamente } \\
\text { vulnerável em qualquer surto de doença infecciosa. Grande } \\
\text { parte do manejo obstétrico é baseada em recomendações } \\
\text { de consenso e melhores práticas, à medida que os dados } \\
\text { de eficácia clínica em relação à terapia antiviral e ao uso de } \\
\text { corticosteróides estão evoluindo. }\end{array}$ \\
\hline Stuebe $A .^{(36)}$ & $\begin{array}{l}\text { Should Infants Be Separated from } \\
\text { Mothers with COVID-19? First, Do No } \\
\text { Harm }\end{array}$ & $\begin{array}{l}\text { Breastfeeding } \\
\text { Medicine }\end{array}$ & $\begin{array}{l}\text { Inglês } \\
\text { EUA } \\
08 / 05 / 2020\end{array}$ & $\begin{array}{l}0 \text { artigo traz várias considerações contrárias sobre o possivel } \\
\text { benefício de separar mãe e filho afim de minimizar o risco de } \\
\text { transmissão do SARS-CoV-2, considerando que o objetivo seja } \\
\text { saúde e bem-estar da mãe e criança também nos meses que } \\
\text { seguem ao nascimento. }\end{array}$ \\
\hline $\begin{array}{l}\text { Calil VMLT, Krebs VU, } \\
\text { Carvalho WB de. } .^{(37)}\end{array}$ & $\begin{array}{l}\text { Guidance on breastfeeding during the } \\
\text { COVID-19 pandemic }\end{array}$ & $\begin{array}{l}\text { REV ASSOC MED } \\
\text { BRAS }\end{array}$ & $\begin{array}{l}\text { Inglês } \\
\text { Brasil } \\
15 / 05 / 2020\end{array}$ & $\begin{array}{l}\text { Os benefícios do AM superam qualquer potencial risco de } \\
\text { transmissão do vírus através do leite. Recomenda-se que } \\
\text { mulheres infectadas pelo COVID-19 que desejem amamentar, } \\
\text { devem ser encorajadas a fazê-lo. A OMS, o MS,a SSSP, A } \\
\text { Rede Brasileira Bancos de Leite Humano, a SBP e a AAP, } \\
\text { recomendam que o AM deve ser mantido com as precauções } \\
\text { necessárias. Esta diretriz é válida se a mãe deseja amamentar } \\
\text { o seu filho e está em condições clínicas de fazê-lo. } 0 \text { contato } \\
\text { pele a pele na sala de parto e a amamentação na } 1^{0} \text { hora } \\
\text { de vida devem ser suspensos. Puérperas devem ficar alojadas } \\
\text { com os seus bebês uma vez que são assintomáticas, com } \\
\text { uma distância de } 2 m \text { entre a cama da mãe e o berço. Se a } \\
\text { mulher não se sentir segura para amamentar enquanto estiver } \\
\text { infectada, recomenda-se a extração do leite para que seja } \\
\text { oferecido fresco ao bebê. }\end{array}$ \\
\hline $\begin{array}{l}\text { Thi Tran H, Thi Kim } \\
\text { Nguyen P, Thi Li H, } \\
\text { Hoang Minh Le C, } \\
\text { Giang HTN, Nguyen } \\
\text { Thi Thu P, et al. }{ }^{(38)}\end{array}$ & $\begin{array}{l}\text { Appropriate care for neonates born to } \\
\text { mothers with COVID-19 disease }\end{array}$ & Acta Paediatrica & $\begin{array}{l}\text { Inglês } \\
\text { Singapura } \\
16 / 06 / 2020\end{array}$ & $\begin{array}{l}\text { Os dados atualmente disponíveis sugerem que o contato } \\
\text { prolongado pele a pele e a amamentação precoce e } \\
\text { exclusiva ainda são as melhores estratégias para reduzir a } \\
\text { morbimortalidade tanto para a mãe com COVID - } 19 \text { quanto } \\
\text { para o bebê, em conjunto com medidas rigorosas de prevenção } \\
\text { e controle de infecções. }\end{array}$ \\
\hline
\end{tabular}


Quadro 3. Síntese das revisões sistematizadas contendo os principais resultados que interferem sobre a prática do Aleitamento Materno

\begin{tabular}{|c|c|c|c|c|c|}
\hline Título & Periódico & \begin{tabular}{|l} 
Língua \\
País \\
Data da \\
publicação
\end{tabular} & Objetivo & Método & Principais resultados sobre 0 aleitamento materno \\
\hline $\begin{array}{l}\text { COVID-19 and } \\
\text { newborn health: } \\
\text { systematic } \\
\text { review }^{(17)}\end{array}$ & $\begin{array}{l}\text { Rev } \\
\text { Panam Salud } \\
\text { Publica }\end{array}$ & $\begin{array}{l}\text { Inglês } \\
\text { EUA } \\
2020\end{array}$ & $\begin{array}{l}\text { Descrever os } \\
\text { resultados } \\
\text { perinatais e } \\
\text { neonatais em } \\
\text { recém-nascidos } \\
\text { expostos à SARS- } \\
\text { CoV-2. }\end{array}$ & $\begin{array}{l}\text { Revisão Sistemática. } \\
\text { Banco de dados: PubMed } \\
\text { Central, LILACS e Google } \\
\text { Scholar. } \\
\text { Palavras-chave 'COVID' AND } \\
\text { 'recém-nascido' OU 'criança' } \\
\text { OU 'bebê'. } \\
\text { Período: } 18 \text { de março de } 2020 \\
\text { e novamente em } 17 \text { de abril } \\
\text { de } 2020 .\end{array}$ & $\begin{array}{l}\text { Do total de } 256 \text { foram elegíveis } 20 \text { artigos. } \\
\text { A determinação de separar ou não uma mãe de COVID-19 } \\
\text { conhecido ou suspeito e seu bebê deve ser feita caso a } \\
\text { caso, usando a tomada de decisão compartilhada entre a } \\
\text { mãe e a equipe clínica. } \\
\text { Parece que o contato pele a pele e a amamentação } \\
\text { podem ser recomendados, mas é fundamental rastrear as } \\
\text { gestantes, implementar medidas de prevenção e controle } \\
\text { e monitorar de perto os recém-nascidos com risco de } \\
\text { COVID-19. } \\
\text { A literatura atual não apoia uma recomendação para se } \\
\text { abster de amamentar com base na falta de evidências } \\
\text { sobre a presença do vírus no leite materno. } \\
\text { Não há evidências suficientes para recomendar a } \\
\text { separação das mães e dos recém-nascidos. }\end{array}$ \\
\hline $\begin{array}{l}\text { SARS-CoV-2 } \\
\text { and human } \\
\text { milk: What is the } \\
\text { evidence? }{ }^{(18)}\end{array}$ & $\begin{array}{l}\text { Maternal \& } \\
\text { Child Nutrition }\end{array}$ & $\begin{array}{l}\text { Inglês } \\
\text { EUA } \\
30 / 05 / 2020\end{array}$ & $\begin{array}{l}\text { Avaliar as } \\
\text { evidências } \\
\text { publicadas sobre } \\
\text { a presença de } \\
\text { SARS-COV-2 } \\
\text { e de outros } \\
\text { cronavírus } \\
\text { humanos no leite } \\
\text { humano. }\end{array}$ & $\begin{array}{l}\text { Pesquisa bibliográfica. } \\
\text { Base de dados: PubMed, } \\
\text { Google Scholar, Medline, } \\
\text { Web of Science. Palavras- } \\
\text { cheve: 'leite humano' ou } \\
\text { 'amamentação' ou “lactação" } \\
\text { 'COVID-19' ou 'coronavírus' ou } \\
\text { 'SARS-CoV-2'. } \\
\text { Revisados os artigos } \\
\text { publicados até } 17 \text { de abril de } \\
2020 .\end{array}$ & $\begin{array}{l}14 \text { estudos selecionados. } \\
\text { A confiança e segurança sobre a práticas da } \\
\text { amamentação durante a infeçãa materna por COVID- } 19 \\
\text { foi comprometida pela falta de evidências se o SARS - } \\
\text { COV- } 2 \text { pode ser transmitido verticalmente no leite e / ou } \\
\text { durante a amamentação. } \\
\text { Evidências limitadas e fracas sugerem que alguns } \\
\text { coronavírus (incluindo SARS - CoV - 2) podem estar } \\
\text { presentes no leite humano, mas esses estudos não } \\
\text { relatam métodos de coleta e validação de ensaios de } \\
\text { reação em cadeia da polimerase com transcrição reversa } \\
\text { (RT - PCR) para leite humano. } \\
\text { Nada se sabe sobre o momento da resposta do anticorpo } \\
\text { no leite humano à infecção por SARS- CoV-2. }\end{array}$ \\
\hline $\begin{array}{l}\text { Infección por } \\
\text { coronavirus } \\
\text { COVID-19 } \\
\text { y lactancia } \\
\text { materna: } \\
\text { una revisión } \\
\text { exploratoria }^{(19)}\end{array}$ & $\begin{array}{l}\text { Rev Esp Salud } \\
\text { Públic }\end{array}$ & $\begin{array}{l}\text { Espanhol } \\
\text { Espanha } \\
27 / 05 / 2020\end{array}$ & $\begin{array}{l}\text { Investigar o plano } \\
\text { de ação sobre } \\
\text { amamentação } \\
\text { em } \\
\text { puérperas com } \\
\text { SARS-CoV-2 } \\
\text { e seu recém- } \\
\text { nascido. }\end{array}$ & $\begin{array}{l}\text { Revisão exploratória. } \\
\text { Banco de dados: Medline, Web } \\
\text { of Science, Scopus, Bancos de } \\
\text { dados BVS e Cuiden. Palavras- } \\
\text { chave "amamentação" AND } \\
\text { "COVID" AND “coronavírus" } \\
\text { AND “leite humano". Período: } \\
27 \text { de abril de } 2020 \text { e } \\
\text { novamente em } 29 \text { de abril de } \\
2020 .\end{array}$ & $\begin{array}{l}\text { Do total de } 324 \text { foram elegíveis } 14 \text { artigos. } \\
\text { É altamente recomendado que as puérperas com SARS- } \\
\text { CoV-2 amamentem seus filhos se a saúde da mãe e do } \\
\text { recém-nascido permitir. } \\
\text { Quando a amamentação é favorecida, as medidas } \\
\text { apropriadas de cuidados e higiene devem ser } \\
\text { consideradas. } \\
\text { Se a saúde da mãe não permite a amamentação, o } \\
\text { leite materno deve ser ordenhado e oferecido sem a } \\
\text { necessidade de pasteurização. } \\
\text { Em situações que a mãe não poder oferecer seu leite } \\
\text { devido a incompatibilidade medicamentosa, considerar a } \\
\text { opção dos bancos de leite. }\end{array}$ \\
\hline $\begin{array}{l}\text { Breastfeeding } \\
\text { of infants born } \\
\text { to mothers with } \\
\text { COVID-19: a } \\
\text { rapid review(32) }^{(32}\end{array}$ & $\begin{array}{l}\text { ATM: Ann Trans/ } \\
\text { Med }\end{array}$ & $\begin{array}{l}\text { Inglês } \\
\text { China } \\
30 / 05 / 2020\end{array}$ & $\begin{array}{l}\text { Realizar uma } \\
\text { rápida revisão da } \\
\text { transmissão de } \\
\text { mãe para filho } \\
\text { do COVID-19 } \\
\text { durante a } \\
\text { amamentação }\end{array}$ & $\begin{array}{l}\text { Revisão Sistemática. } \\
\text { Banco de dados: MEDLINE, } \\
\text { Embase, Web of Science, } \\
\text { Cochrane Library, disco } \\
\text { China Biology Medicine, } \\
\text { China National Knowledge } \\
\text { Infrastructure, Wanfang até } \\
\text { março de 2020. Incluídos } \\
\text { estudos relevantes à } \\
\text { transmissão através de leite e } \\
\text { gotículas respiratórias durante } \\
\text { a amamentação de mães } \\
\text { com COVID-19, SARS, MERS } \\
\text { e gripe. }\end{array}$ & $\begin{array}{l}\text { Do total de } 4.481 \text { foram elegíveis } 6 \text { artigos. } \\
\text { Não há evidências de ácido nucleico viral detectado no } \\
\text { leite materno de mães com COVID-19. } \\
0 \text { uso de máscaras e a higiene das mãos pode reduzir } \\
\text { o risco de transmissão através de gotículas e contato } \\
\text { próximo durante a amamentação. } \\
\text { É provável que os benefícios da amamentação superem o } \\
\text { risco de infecção por COVID-19 em bebês. } \\
\text { As precauções eficazes que recomendamos podem reduzir } \\
\text { o risco, mas não evitar a transmissão do SARS-CoV-2. }\end{array}$ \\
\hline
\end{tabular}


Continuação.

\begin{tabular}{|c|c|c|c|c|c|}
\hline $\begin{array}{l}\text { Care of newborns } \\
\text { born to mothers } \\
\text { with COVID-19 } \\
\text { infection; a } \\
\text { review of existing } \\
\text { evidence }^{(33)}\end{array}$ & $\begin{array}{l}\text { The Journal of } \\
\text { Maternal-Fetal } \\
\text { \& Neonatal } \\
\text { Medicine }\end{array}$ & $\begin{array}{l}\text { Inglês } \\
\text { EUA } \\
23 / 06 / 2020\end{array}$ & \begin{tabular}{|l|} 
Discutir como \\
cuidar de um \\
recém-nascido \\
de uma mãe \\
suspeita ou \\
infectada com \\
COVID-19 usando \\
evidências \\
existentes
\end{tabular} & $\begin{array}{l}\text { Revisão sistemática referente } \\
\text { a } 1 \text { de janeiro de } 2020 \\
\text { até } 30 \text { de março de } 2020 . \\
\text { Incluído PubMed e Google } \\
\text { Scholar para pesquisa. } \\
\text { Palavras-chave do Mesh: } \\
\text { COVID-19 e gravidez; SARS- } \\
\text { CoV-2 e gravidez; Coronavírus } \\
\text { e gravidez; 2019-nCoV e } \\
\text { gravidez. Todos equivalentes } \\
\text { com amamentação, cuidados } \\
\text { neonatais e recém- } \\
\text { nascidos, como CovID-19 e } \\
\text { amamentação; SARS-CoV-2 e } \\
\text { cuidados neonatais; e recém- } \\
\text { nascido. CovID-19 e cuidados } \\
\text { neonatais e assim por diante. }\end{array}$ & $\begin{array}{l}\text { Do total de } 1.461 \text { foram elegiveis } 57 \text { artigos. } \\
\text { A amamentação deve ser incentivada em mães infectadas } \\
\text { ou suspeitas com base na tomada de decisões. Em caso } \\
\text { de dúvida, uma alternativa também seria a mamadeira } \\
\text { para oferecer o leite extraído. } \\
\text { A mãe e outros membros da família devem ser } \\
\text { aconselhados a desinfetar a bomba ou outros recipientes } \\
\text { de leite com agentes à base de hipoclorito de sódio. } \\
\text { Antes da alta, as mães devem ser ensinadas sobre } \\
\text { condições que podem ajudar na extração. } \\
\text { Se os pais decidirem consumir a fórmula, ensine-os a } \\
\text { limpar bem a mamadeira. } \\
\text { Quando o bebê não é colocado no seio materno, os } \\
\text { problemas causados pela estase do leite devem ser } \\
\text { explicados à mãe. } \\
\text { A pessoa que vai cuidar do bebê durante duas semanas } \\
\text { de isolamento deve ser ensinada a amamentar o bebê e } \\
\text { os princípios de higiene pessoal devem ser enfatizados, } \\
\text { incluindo lavagem regular das mãos e EPI. }\end{array}$ \\
\hline $\begin{array}{l}\text { Improving the } \\
\text { quality of care } \\
\text { in pregnancy } \\
\text { and childbirth } \\
\text { with coronavirus } \\
\text { (COVID-19): } \\
\text { a systematic } \\
\text { review }^{(34)}\end{array}$ & $\begin{array}{l}\text { The Journal of } \\
\text { Maternal-Fetal } \\
\text { \& Neonatal } \\
\text { Medicine }\end{array}$ & $\begin{array}{l}\text { Inglês } \\
\text { Irã } \\
14 / 05 / 2020\end{array}$ & $\begin{array}{l}\text { Revisar a } \\
\text { literatura } \\
\text { disponível sobre } \\
\text { gravidez e parto } \\
\text { com coronavírus }\end{array}$ & $\begin{array}{l}\text { Revisão Sistemática. As } \\
\text { pesquisas foram realizadas } \\
\text { até } 25 \text { de março de } 2020 . \\
\text { Utilizado como palavras-chave, } \\
\text { (“COVID-19 OU coronavírus } \\
\text { OU 2019-nCoV”) E (gravidez } \\
\text { OU parto). Pesquisado em: } \\
\text { PubMed, Scopus, Embase, } \\
\text { Seciencedirect, Clinikalkey, a } \\
\text { língua inglesa. }\end{array}$ & $\begin{array}{l}\text { Do total de } 375 \text { foram elegíveis } 32 \text { artigos. } \\
\text { É essencial proteger e separar os bebês das mães com } \\
\text { COVID-19 imediatamente após o nascimento por pelo } \\
\text { menos } 14 \text { dias. } \\
\text { As mães que pretendem amamentar devem ser } \\
\text { incentivadas a ordenhar seu leite a fim de manter a } \\
\text { produção láctea. A bomba de ordenha deve ser de uso } \\
\text { exclusivo. As mães devem praticar a higiene das mãos } \\
\text { antes de ordenhar o leite materno. Após cada sessão } \\
\text { de ordenha, todas as peças que entram em interação } \\
\text { com o leite devem ser lavadas e toda a bomba deve ser } \\
\text { esterilizada de acordo com as instruções do fabricante. Se } \\
\text { a mãe desejar amamentar, ela deve colocar uma máscara } \\
\text { facial e praticar a higiene das mãos antes de cada } \\
\text { mamada. Bebês cujas mães estão confirmadas com } \\
\text { CovID-19 não devem ser alimentados com leite materno. }\end{array}$ \\
\hline $\begin{array}{l}\text { To breastfeed } \\
\text { or not to } \\
\text { breastfeed? Lack } \\
\text { of evidence on } \\
\text { the presence of } \\
\text { SARS-CoV-2 in } \\
\text { breastmilk of } \\
\text { pregnant women } \\
\text { with COVID-19(35) }\end{array}$ & $\begin{array}{l}\text { Pan American } \\
\text { Journal of } \\
\text { Public Health }\end{array}$ & $\begin{array}{l}\text { Inglês } \\
\text { China } \\
\text { 29/05/2020 }\end{array}$ & $\begin{array}{l}\text { Avaliar as } \\
\text { evidências atuais } \\
\text { relacionadas } \\
\text { à presença da } \\
\text { SARS-CoV-2 no } \\
\text { leite materno de } \\
\text { mulheres grávidas } \\
\text { com COVID-19. }\end{array}$ & $\begin{array}{l}\text { Revisão sistemática. } \\
\text { Verificou a presença de RNA } \\
\text { do SARS-CoV-2 no leite } \\
\text { materno de } 24 \text { gestantes } \\
\text { com COVID-19 durante o } 3^{\circ} \\
\text { trimestre de gravidez. Bases } \\
\text { pesquisadas: PubMed, Web } \\
\text { of Science, Scopus, banco } \\
\text { de dados National da China } \\
\text { e literatura cinzenta (Google } \\
\text { Scholar e repositórios de } \\
\text { pré-impressão). Pesquisas } \\
\text { realizadas até } 30 / 03 \text { e } \\
\text { atualizadas em 21/04/2020. }\end{array}$ & $\begin{array}{l}\text { Oito estudos selecionados. } \\
\text { RN de mães com suspeita ou confirmação de COVID-19 } \\
\text { devem ser isolados por pelo menos } 14 \text { dias e não devem } \\
\text { ser amamentados. } 0 \text { ato da amamentação deve ser } \\
\text { determinado pela mãe com sua família e profissionais } \\
\text { de saúde com todas as medidas de prevenção possíveis } \\
\text { incluindo o uso de máscara e a lavagem das mãos e seios } \\
\text { com sabão e água antes da amamentação. No caso de } \\
\text { ordenha do leite materno, todas as recomendações para } \\
\text { a limpeza dos bicos e utensílios após cada uso devem ser } \\
\text { rigorosamente seguidas. Considerar a possibilidade de } \\
\text { alguém saudável fornecer leite materno ao bebê usando } \\
\text { um copo ou colher. Se não houver produção de leite } \\
\text { materno pela mãe, um banco de leite humano deve ser } \\
\text { contatado. }\end{array}$ \\
\hline $\begin{array}{l}\text { Novel } \\
\text { Coronavirus } \\
\text { disease } \\
\text { (COVID-19) in } \\
\text { newborns and } \\
\text { infants: what we } \\
\text { know so far }{ }^{(39)}\end{array}$ & $\begin{array}{l}\text { Italian Journal } \\
\text { of Pediatrics }\end{array}$ & $\begin{array}{l}\text { Inglês } \\
\text { Itália } \\
\text { 29/04/2020 }\end{array}$ & $\begin{array}{l}\text { Oferecer uma } \\
\text { visão geral do } \\
\text { conhecimento } \\
\text { sobre } \\
\text { epidemiologia } \\
\text { e a transmissão } \\
\text { do SARS-COV-2 } \\
\text { e apresentação } \\
\text { dos resultados de } \\
\text { recém-nascidos } \\
\text { e bebês até } 6 \\
\text { meses de vida. }\end{array}$ & $\begin{array}{l}\text { Pesquisa bibliográfica. Base } \\
\text { de dados: PubMed e Google. } \\
\text { Palavras-cheve: 'neonatos' } \\
\text { AND 'recém-nascidos' AND } \\
\text { 'COVID-19' AND '2019- } \\
\text { nCoV' ou 'SARS-CoV-2'. Sem } \\
\text { restrições de data, ano, } \\
\text { localizações, desenho do } \\
\text { estudo, objetivo do estudo, } \\
\text { ou critérios de inclusão / } \\
\text { exclusão. Revisados os artigos } \\
\text { publicados até 07/04/2020. }\end{array}$ & $\begin{array}{l}\text { Não é possível confirmar a transmissão de SARS-CoV-2 } \\
\text { através do leite materno diante a limitação de dados sobre } \\
\text { a excreção do vírus no leite materno. Essa é a razão pela } \\
\text { qual a maioria das diretrizes neonatais não contraindica } \\
\text { a amamentação de mães com COVID-19. No entanto, é } \\
\text { necessário tomar precauções específicas como usar uma } \\
\text { máscara durante a amamentação e a higienização das } \\
\text { mãos. }\end{array}$ \\
\hline
\end{tabular}




\section{Discussão}

Com pouco mais de 6 meses do início da pandemia, temos acompanhado um número assustadoramente crescente de publicações sem que novas ou significativas evidências tenham sido descobertas no que diz respeito aos cuidados perinatais. Os cuidados precoces essenciais ao RN consistem em um pacote de simples intervenções baseadas em evidências dispensados em torno do nascimento. ${ }^{(13)}$ Entre eles, merece destaque o AM e o contato pele a pele nos casos de mãe infectada ou suspeita por COVID-19, como os pontos mais divergentes até o momento encontrados. O surgimento da pandemia não modifica os benefícios advindos dessas práticas e, ao contrário, elas se sobrepõem aos malefícios do potencial risco de transmissão da COVID-19 em uma população que, em geral, não tem demonstrado formas graves de manifestação da doença.

Apesar de várias publicações versarem sobre transmissibilidade e detecção do vírus, todavia, são escassas as pesquisas com delineamentos e potencial para elucidar as lacunas referentes à transmissibilidade do SARS-CoV-2 relacionados ao AM. A maior parte deles são relatos de casos bem documentados e os métodos de detecção, bem como os intervalos entre as coletas são bastante diversificados com resultados inconsistentes. A falta de um método analítico de detecção bem descrito e consagrado como "padrão ouro" especialmente desenvolvido para o leite humano contribui para a falta de credibilidade dos achados, dada a sua complexidade na composição. ${ }^{(14,15)}$

Dentre os estudos obtidos há predominância dos desenvolvidos na China, o que pode ser justificado pelo fato deste país ter registrado os casos iniciais de COVID-19 e ter intensificado as pesquisas desde então.

Há divergências entre os pesquisadores quanto ao estabelecimento da amamentação por mães suspeitas ou confirmadas de SARS-CoV-2. Essa discrepância muito se deve pelos resultados contraditórios das pesquisas, visto que em algumas não foram encontrados indícios de SARS-CoV-2 no leite materno e, portanto, a amamentação é recomendada. ${ }^{(14,16,17)}$ Nos estudos em que a presença do vírus foi confirmada ${ }^{(15,18-20)}$ os autores a contraindicam.

Entre os estudos, há um relato de caso da China, ${ }^{(16)}$ cujos autores, mesmo não tendo detectado sinais do vírus no leite materno, indicam isolamento de 14 dias entre mãe e filho pelo risco de contágio. Justificam esse posicionamento pelos poucos casos relatados na literatura, o que dificulta uma clara definição dos riscos e, consequentemente, dúvidas sobre quais orientações devem ser fornecidas às pacientes. Sendo assim, sugerem também que a amamentação seja estabelecida somente quando a testagem da mãe for negativa para o SARS-CoV-2.

A possibilidade de transmissão pelo leite materno foi mencionada em parte dos estudos, ${ }^{(15,20)}$ assim como a transmissão vertical ${ }^{(14,20)}$ em função da presença de alto nível de IgG para SARS-CoV-2 no bebê, observado apenas com 1,5 mês de vida, indicando a transmissão placentária de anticorpos, visto que teve resultado negativo para o RNA do vírus logo após o parto. O anticorpo IgG da mãe geralmente permanece no neonato por mais de 6 meses após o nascimento. Este é um dado importante pois os bebês, incapazes de produzir imunoglobulinas, são protegidos por anticorpos maternos por até 12 meses após o nascimento

Pesquisadores relatam um caso na Austrália, ${ }^{(19)}$ com resultado positivo para o coronavírus em duas amostras de leite materno, com 10 dias de intervalo entre elas, intercaladas com vários resultados negativos. No entanto, levantaram a hipótese de que possa ter ocorrido contaminação da orofaringe do bebê para a mama, visto que detectaram por 66 dias o RNA do vírus nas suas fezes. Alertam que é desconhecido o mecanismo de excreção viral no tecido mamário e que, provavelmente, os benefícios do AM superam os riscos associados à infecção materna por COVID-19. O significado desse achado é incerto, pois o RNA detectável nessas amostras não demonstrou indicar vírus viáveis ou demonstrar risco de infecção pelo AM. Assim sendo, a paciente, apesar de ter vírus detectável no leite humano, continuou amamentando seu bebê sem efeitos adversos.

Vale destacar, que foram detectados anticorpos IgG e IgA para SARS-CoV-2 no leite materno, indicando potencial proteção imunológica para os neonatos. (14,19-21) Os pesquisadores realçam a importância da amamentação, visto que protege os bebês contra infecções principalmente por meio de anticorpos secretores de IgA (SIgA). Nos estágios iniciais da lactação, IgA, fatores anti-inflamatórios e, mais provavelmente, célu- 
las imunologicamente ativas fornecem suporte adicional para o sistema imunológico imaturo do neonato.

Estudo realizado na Turquia ${ }^{(14)}$ determinou a presença do SARS-CoV-2 no colostro de uma puérpera com COVID-19, porém assintomática, logo nas primeiras horas pós-parto (8, 72 e 96 horas). No entanto, o swab nasofaríngeo do $\mathrm{RN}$ realizado logo após o parto foi negativo. Os pesquisadores levantaram a hipótese de falso negativo pois amostras semelhantes de swab nasofaríngeo obtidas em momentos posteriores foram positivas. Entretanto, os autores não mencionam se o bebê apresentou sintomas da COVID-19, apenas que na alta seu swab nasofaríngeo foi negativo.

Cronologicamente os posicionamentos relacionados com recomendar a amamentação ou proibi-la foram se modificando ao longo do tempo, o que compromete a adesão dos profissionais que estão na prática e a credibilidade dos órgãos consistentemente respeitados. É esperado e compreensível a dinâmica das descobertas e consequentemente as mudanças das diretrizes, mas chamamos novamente a atenção para este cuidado de que, enquanto vários conhecimentos permanecerem obscuros, não ameacemos aqueles bem conhecidos. A infecção por COVID-19 em bebês e crianças representa uma ameaça bem menor à sobrevida e saúde do que outras infecções, contra as quais o aleitamento materno protege. ${ }^{(22)}$ Os benefícios do aleitamento materno e do estímulo ao vínculo mãe-bebê, na prevenção de infecções e promoção da saúde e do desenvolvimento, são especialmente importantes quando os serviços comunitários e de saúde estão fechados ou limitados. ${ }^{(22)}$

A maioria das entidades/órgãos governamentais, sociedades de especialidades e associações de classe é favorável à prática da amamentação, desde que sejam adotadas as medidas de segurança, por mães assintomáticas, suspeitas ou COVID-19 confirmadas, com exceção daquelas com quadros graves ou que não desejem. A principal justificativa reside no fato de que não há, até o momento, evidências de que o vírus SARS-CoV2 seja transmitido pelo leite materno. Também alertam que os benefícios do aleitamento materno se sobrepõem em muito aos riscos do COVID-19 nessa população. .23-26) $^{2}$

Enquanto as evidências não comprovarem consistentemente o contrário, acredita-se que a principal rota de transmissibilidade do COVID-19 para os neonatos sejam as gotículas aéreas dos cuidadores, seguido pelo contato com material biológico contaminado, essencialmente durante o período pós-natal, quando os neonatos são expostos a mães, outros cuidadores, visitantes ou profissionais de saúde com o COVID-19.(6,7)

Portanto, o uso de máscaras e a higiene das mãos podem diminuir notavelmente a possibilidade de transmissão do vírus respiratório. ${ }^{(27)} \mathrm{Ou}$ seja, a amamentação com as devidas precauções, pode reduzir o risco de transmissão da mãe para o bebê, embora não seja totalmente evitável.

Se uma mãe infectada ou suspeita for assintomática ou apresentar sintomas leves, a amamentação é aconselhada, mas se ela estiver muito doente para cuidar do RN, o mesmo deve ser cuidado separadamente e alimentado com leite materno fresco ofertado por uma terceira pessoa saudável. ${ }^{(28)}$ Durante a separação, a mãe deve ser incentivada a extrair seu leite a fim de manter a produção láctea com uma bomba de uso exclusivo ${ }^{(29)}$ e todas as recomendações para a limpeza dos bicos e utensílios após cada uso devem ser rigorosamente seguidas. Nos casos de diminuição da produção láctea materna, além da recomendação de aumento da frequência do estímulo e esvaziamento mamário, um banco de leite humano pode ser contatado considerando que até o momento, não há restrições quanto ao uso de leite processado nesses locais. (30) A OMS recomenda que as mulheres suspeitas ou comprovadamente infectadas com COVID-19 possam amamentar seus bebês diretamente no peito ou com seu leite ordenhado, ou ainda usando leite de doadora. (22) Também orienta que a escolha pela amamentação seja determinada pela mãe, juntamente com sua família e profissionais de saúde. Preconiza que todas as medidas de prevenção possíveis para evitar a propagação do vírus ao bebê devem ser tomadas, incluindo o uso de uma máscara e a lavagem das mãos e mamas com sabão e água antes da amamentação.

Embora os chineses provavelmente continuem acreditando na possibilidade da transmissão vertical e pelo leite humano. Face a essa crença, continuam recomendando a separação da díade desde o nascimento até pelo menos 14 dias ou o desaparecimento do vírus no controle de secreções maternas. ${ }^{(29)}$

A separação entre mãe e filho logo ao nascimento, além de não garantir a prevenção da infecção neonatal por COVID-19, pode levar a uma constelação de doen- 
ças e mortes evitáveis entre bebês e mulheres em todo o mundo. ${ }^{(10)}$ Tal recomendação favorece a descontinuidade da amamentação no período pós-COVID-19 visto que o uso de quaisquer outros utensílios para oferecer o leite que não sejam as mamas podem levar à confusão de bicos e ao desmame precoce.

Separar as mães de seus bebês, especialmente no contexto de ter sido diagnosticada com a doença da pandemia em curso, pode causar estresse e sofrimento desnecessários que podem piorar para o curso da doença materna. ${ }^{(31)}$ Ao contrário, manter a mãe junto a seu bebê certamente irá beneficiá-la do ponto de vista emocional, contribuindo para o enfrentamento das dificuldades inerentes ao período de isolamento social. ${ }^{(32)}$

Não praticar o contato pele a pele logo ao nascimento pode interromper a fisiologia natural de adaptação do RN; a separação estressa as mães, interfere na provisão do leite materno podendo interrompê-lo. Não amamentar aumenta o risco de hospitalização por pneumonia e o isolamento para separação do binômio dobra o caos do sistema de saúde. ${ }^{(31)}$ Já que até o momento não há evidências que demonstrem que a separação precoce melhora os resultados, então lembremos de primeiramente, não fazer mal. ${ }^{(31)}$

Sobre o contato pele a pele, essa prática protege o RN das consequências negativas dos procedimentos prejudiciais comumente realizados no período perinatal, que incluem clampeamento precoce do cordão, sucção orofaríngea de rotina, banho imediatamente após o parto, as quais podem alterar a fisiologia da adaptação extrauterina imediata e retardar a prontidão do bebê para mamar na primeira hora, entre outros impactos negativos. Dentre eles, vale destacar que essa separação pode aumentar o contato do bebê com vários profissionais de saúde que podem estar infectados. ${ }^{(33)}$

Outra importante ponderação é a possibilidade de que, ao receber alta, o bebê possa ser infectado por algum membro da família e terá sido em vão o afastamento entre mãe e filho.

Amamentar na primeira hora de vida é outra prática considerada essencial que traz numerosos benefícios, especialmente o colostro que apresenta altas concentrações de imunoglobulinas, transferrina, citocinas, e células imunológicas, as quais são transferidas através do leite materno juntamente com os anticorpos provendo uma potente proteção contra infecções neonatais $^{(33)} \operatorname{logo}$ na chegada ao ambiente. Recomen- da o contato pele a pele, inclusive o método canguru, especialmente logo após o nascimento. ${ }^{(22)}$ Também orienta que as mulheres sejam estimuladas a iniciar ou continuar o AM, mesmo que elas ou seus bebês sejam suspeitos ou confirmados de COVID-19, além de receberem orientações quanto aos benefícios da amamentação superarem, consideravelmente, os riscos potenciais de transmissão.

Entretanto, algumas diretrizes nacionais e internacionais, elaboradas antes de 23/06/2020, recomendam que nos casos de mãe infectada ou suspeita de COVID-19, o AM e contato pele a pele não devem ser realizados imediatamente ao nascer, mas somente após as primeiras medidas de higiene. ${ }^{(6,7)}$

Os pesquisadores que recomendam a amamentação enfatizam que esta deve ser uma decisão conjunta entre a puérpera e a equipe, e que todas as medidas recomendadas devem ser observadas para proteger o neonato. ${ }^{(14,17,20)}$

Sobre a decisão de amamentar ou não o seu bebê ficar sob responsabilidade materna, faz-se imprescindível que a mulher esteja bem informada sobre a ausência de dados, até o momento, que confirmem a transmissão vertical e infecção através do leite humano, aliados a todos os benefícios de proteção do seu bebê com a manutenção do AM a longo prazo e a redução de morbidade em tempos como estes. ${ }^{(32)}$

Quanto à recomendação de extração do leite quando a mulher não puder/quiser amamentar, ${ }^{(16,20)}$ deve ser considerada uma alternativa para redução de danos considerando a oferta do leite humano que pode beneficiar o RN em termos imunológicos. No entanto, a tarefa de retirar o próprio leite em todas as mamadas dificulta o processo do AM, causando, entre outros, cansaço e desgaste, o que pode favorecer o abandono de tal prática e a adoção da fórmula infantil pela mãe.

Por esse motivo entre outros, em tempos de pandemia, altos estoques de leite nos Bancos de Leite Humano (BLH) seriam mais que bem-vindos para atender não somente os casos de prematuridade que, costumeiramente, são os maiores consumidores, mas também aos filhos das mulheres infectadas que por algum motivo não pudessem oferecer seu próprio leite. Sendo assim, as doações maternas que tendem a se reduzir neste período, requerem estímulo, incentivo e até mesmo campanhas que assegurem essa forma de subsistência. 
Os BLH não devem usar leite de mães confirmadas com COVID-19, daí a necessidade de controle das doadoras além do leite doado ser liberado para uso após a triagem de SARS-CoV-2, considerando o período de incubação. ${ }^{(29)}$ Entre esta e várias outras recomendações, o funcionamento dos BLH também requer um conjunto de cuidados rigorosos adicionais àqueles de costume quanto à coleta, processamento, armazenamento e distribuição do leite humano. ${ }^{(34)}$

Outra medida que cabe acrescentar é a necessidade da permanência de pelo menos um acompanhante, a fim de apoiar e auxiliar a mulher em um momento de tamanha vulnerabilidade emocional e física para tomar as decisões e cuidar sozinha do seu bebê recém-chegado, o que nem sempre tem sido devidamente respeitado de acordo com as leis que asseguram o direito ao acompanhante nesse período.

Algumas das prioridades urgentes apontadas para a elucidação das lacunas de conhecimento relacionadas à atenção perinatal existentes é a realização de estudos longitudinais mais amplos, que possam fornecer dados definitivos sobre as taxas de infecção de RN de mães com COVID-19 com e sem separação, crianças de mães infectadas com AM direto, tanto para partos vaginais quanto para cesarianas. ${ }^{(33)}$

\section{Conclusão}

A falta de evidências para fundamentar as recomendações e tomada de decisões, em tese, a favor de um risco potencial para transmissão e infecção por COVID-19 em contraposição ao AM, pode influenciar no processo de interação e vínculo entre mãe e bebê, interferindo no sucesso da amamentação e aumentar, potencialmente, uma cascata de doenças e mortes preveníveis entre mulheres e crianças em todo mundo. Considerando os benefícios solidamente comprovados pela pratica do AM precoce e duradouro, balanceados com os malefícios advindos das manifestações da infecção por COVID-19, geralmente leves nas crianças e gestantes, essa revisão aponta um pacote de cuidados que integram a preocupação com a sua prevenção nos $\mathrm{RN}$, com a manutenção da proximidade entre mãe e bebê e amamentação como o caminho mais apropriado para o conhecimento produzido até o momento. As precauções recomendadas podem re- duzir o risco, mas não evitar a transmissão do SARS-CoV-2, assim como o afastamento entre mãe e RN e a suspensão do AM também não apresentaram evidências de eficácia. Equipamentos de proteção individual adequados, recursos para higienização das mãos e cuidadoso aconselhamento das mães e famílias a respeito das evidências existentes e dos cuidados preventivos são essenciais para que se possa adotar precauções eficazes. Os protocolos de cuidados institucionais e os profissionais de saúde devem ser constantemente atualizados visando modificar e controlar as práticas recomendadas a fim de prevenir a infecção para todos.

\section{Referências}

1. Stanojević M. Are COVID-19-positive mothers dangerous for their term and well newborn babies? Is there an answer? J Perinat Med. 2020;48(5):441-5.

2. Rollins NC, Lutter CK, Bhandari N, Hajeebhoy N, Horton S, Martines JC, et al. Por que investir e 0 que será necessário para melhorar as práticas de amamentação? Epidemiol Serv Saúde. 2016;25(1):25-44.

3. Victora CG, Bahl R, Barros AJ, França GV, Horton S, Krasevec J, et al. Breastfeeding in the 21st century: epidemiology, mechanisms, and lifelong effect. Lancet. 2016;387(10017):47590.

4. Walters DD, Phan LT, Mathisen R. The cost of not breastfeeding: global results from a new tool. Health Policy Plan. 2019;34(6):407-17.

5. Peroni DG, Fanos V. Lactoferrin is an important factor when breastfeeding and COVID-19 are considered. Acta Paediatr. 2020;109:2139-40.

6. Davanzo R, Moro G, Sandri F, Agosti M, Moretti C, Mosca F. Breastfeeding and coronavirus disease-2019: ad interim indications of the Italian Society of Neonatology endorsed by the Union of European Neonatal \& Perinatal Societies. Matern Child Nutr. 2020;e13010.

7. Roberton T, Carter ED, Chou VB, Stegmuller AR, Jackson BD, Tam Y, et al. Early estimates of the indirect effects of the COVID-19 pandemic on maternal and child mortality in low-income and middle-income countries: a modelling study. Lancet Glob Health. 2020;8(7):901-8.

8. Rasmussen SA, Jamieson DJ. Coronavirus disease 2019 (COVID-19) and pregnancy: responding to a rapidly evolving situation. Obstet Gynecol. 2020;135(5):999-1002.

9. Giuliani C, Li Volsi P, Brun E, Chiambretti A, Giandalia A, Tonutti L, et al. Breastfeeding during the COVID-19 pandemic: suggestions on behalf of woman study group of AMD. Diabetes Res Clin Pract. 2020;1-5.

10. Moro GE, Bertino E. Breastfeeding, human milk collection and containers, and human milk banking: hot topics during the COVID-19 pandemic. J Hum Lact. 2020;8:890334420934391

11. Peters MD, Godfrey CM, Mclnerney P, Soares CB, Khalil H, Parker D. The Joanna Briggs Institute reviewers'. Manual 2015: Methodology for JBI scoping reviews. Australia: Joanne Briggs Institue; 2015. p.1-24.

12. Aromataris E, Munn Z, editors. JBI Manual for evidence synthesis. Australia: Joanne Briggs Institue; 2020.

13. Tomori C, Gribble K, Palmquist AE, Ververs M, Gross MS. When separation is not the answer: breastfeeding mothers and infants affected by COVID-19. Matern Child Nutr. 2020;16:e13033.

14. Rajewska A, Mikołajek-Bedner W, Lebdowicz-Knul J, Sokołowska M, Kwiatkowski S, Torbé A COVID-19 and pregnancy-where are we now? A review. J Perinat Med. 2020;48(5):428-34.

15. Marinelli KA, Lawrence RM. Safe handling of containers of expressed human milk in all settings during the SARS-CoV-2 (COVID-19) pandemic. J Hum Lact. 2020;36(3):498-501.

16. Dashraath P, Wong JL, Lim MX, Lim LM, Li S, Biswas A, et al. Coronavirus disease 2019 (COVID-19) pandemic and pregnancy. Am J Obstet Gynecol. 2020;222(6):521-31.

17. Duran P, Berman S, Niermeyer S, Jaenisch T, Forster T, Gomez Ponce de Leon R, et al. COVID-19 and newborn health: systematic review. Rev Panam Salud Pública. 2020;44:e54. 
18. Lackey KA, Pace RM, Williams JE, Bode L, Donovan SM, Järvinen KM, et al. SARS-CoV-2 and human milk: What is the evidence? Matern Child Nutr. 2020;30:e13032.

19. Fernández-Carrasco FJ, Vázquez-Lara JM, González-Mey U, Gómez-Salgado J, ParrónCarreño T, Rodríguez-Díaz L. Infección por coronavirus COVID-19 y lactancia materna: una revisión exploratoria. Rev Esp Salud Pública. 2020;94:e202005055.

20. Dong Y, Chi X, Hai H, Sun L, Zhang M, Xie WF, et al.Antibodies in the breast milk of a maternal woman with COVID-19. Emerg Microbes Infect. 2020;9(1):1467-69.

21. Wu Y, Liu C, Dong L, Zhang C, Chen Y, Liu J, et al. Coronavirus disease 2019 among pregnant Chinese women: case series data on the safety of vaginal birth and breastfeeding. BJOG. 2020;127(9):1109-15.

22. Lang GJ, Zhao H. Can SARS-CoV-2-infected women breastfeed after viral clearance? 2020;21(5):405-7.

23. Pereira A, Cruz-Melguizo S, Adrien M, Fuentes L, Marin E, Perez-Medina T. Clinical course of coronavirus disease-2019 in pregnancy. Acta Obstet Gynecol Scand. 2020;99(7):839-47.

24. Zhu C, Liu W, Su H, Li S, Shereen MA, Lv Z, et al. Breastfeeding risk from detectable severe acute respiratory syndrome coronavirus 2 in breastmilk. J Infect. 2020;81(3):452-82.

25. Tam PC, Ly KM, Kernich ML, Spurrier N, Lawrence D, Gordon DL, et al. Detectable severe acute respiratory syndrome coronavirus 2 (SARS-CoV-2) in human breast milk of a mildly symptomatic patient with coronavirus disease 2019 (COVID-19). Clin Infect Dis. 2020;30:ciaa673.

26. Bastug A, Hanifehnezhad A, Tayman C, Ozkul A, Ozbay 0, Kazancioglu S, et al.Virolactia in an asymptomatic mother with COVID-19. Breastfeed Med. 2020;15(8):1-4.

27. Fox A, Marino J, Amanat F, Krammer F, Hahn-Holbrook J, Zolla-Pazner S, et al. Evidence of a significant secretory-lgA-dominant SARS-CoV-2 immune response in human milk following recovery from COVID-19. medRxiv. 2020 May [cited 2020 Jul 15]. Available from: http:// medrxiv.org/lookup/doi/10.1101/2020.05.04.20089995

28. Organização Panamericana da Saúde (OPAS) Aleitamento materno e a doença causada pelo novo coronavírus (COVID-19). Informações científicas: 23 de junho de 2020. OPAS; 2020 [citado 2020 Jul 24 Disponivel em: https://iris.paho.org/handle/10665.2/52479

29. Associação Brasileira de Obstetrizes e Enfermeiros Obstetras (ABENF0; Associação Brasileira de Enfermagem (ABEN); Conselho Federal de Enfermagem (COFEN), Nota técnica aponta medidas para conter mortes maternas associadas à COVID-19. Alerta às mortes maternas associadas à COVID-19 no Brasil. São Paulo: ABENFO/ABEN/COFEN; 2020 [citado 2020 Set 30]. Disponível em: http://www.cofen.gov.br/nota-tecnica-apontamedidas-para-conter-mortes-maternas-associadas-a-covid-19_81618.html

30. Brasil. Ministério da Saúde. Secretaria de Atenão Primária à Saúde. NOTA TÉCNICA No 10/2020-COCAM/CGCIVI/DAPES/SAPS/MS. Atenção à saúde do recém-nascido no contexto da infecção pelo novo coronavírus (SARS-CoV-2). Brasilia (DF): Ministério da Saúde; 2020 [citado 2020 Jul 20]. Dsiponivel em: https://rblh.fiocruz.br/sites/rblh. fiocruz.br/files/usuario/80/notatecnica102020cocamcgcividapessapsms_003.pdf

31. Brasil. Ministério da Saúde. Secretaria de Atenão Primária à Saúde. NOTA TÉCNICA No 8/2020-COCAM/CGCIVI/DAPES/SAPS/MS. Condutas para a doação de leite materno aos bancos de leite humano e postos de coleta de leite humano no contexto da infecção covid 19 causada pelo novo coronavírus (SARS-cov-2). Brasilia (DF): Ministério da Saúde; 2020 [citado 2020 Jul 20]. Dsiponivel em: https://www.unasus.gov.br/especial/ covid19/pdf/96

32. Yang $\mathrm{N}$, Che $\mathrm{S}$, Zhang J, Wang $\mathrm{X}$, Tang $\mathrm{Y}$, Wang J, et al. Breastfeeding of infants born to mothers with COVID-19: a rapid review. Ann Transl Med. 2020;8(10):618.

33. Sighaldeh SS, Kalan Me. Care of newborns born to mothers with COVID-19 infection; a review of existing evidence. J Matern Fetal Neonatal Med. 2020;23:1-13.

34. Abdollahpour S, Khadivzadeh T. Improving the quality of care in pregnancy and childbirth with coronavirus (COVID-19): a systematic review. J Matern Fetal Neonatal Med. 2020;14:19.

35. Martins-Filho PR, Santos VS, Santos Jr HP. To breastfeed or not to breastfeed? Lack of evidence on the presence of SARS-CoV-2 in breastmilk of pregnant women with COVID-19. Rev Panam Salud Pública. 2020;44:e59.

36. Stuebe A. Should infants be separated from mothers with COVID-19? First, Do No Harm. Breastfeed Med. 2020;15(5):351-2.

37. Calil VM, Krebs VL, Carvalho WB. Guidance on breastfeeding during the COVID-19 pandemic. Rev Assoc Med Bras. 2020;66(4):541-6.

38. Tran HT, Nguyen PT, Huynh LT, Le CH, Giang HT, Nguyen PT, et al. Appropriate care for neonates born to mothers with COVID-19 disease. Acta Paediatr. 2020;109:1713-6.

39. De Rose DU, Piersigilli F, Ronchetti MP, Santisi A, Bersani I, Dotta A. Novel coronavirus disease (COVID-19) in newborns and infants: what we know so far. Ital J Pediatr. 2020;46(1):56. 